\title{
Improved Laboratory Transition Probabilities for Neutral Chromium and Re-determination of the Chromium Abundance for the Sun and Three Stars
}

\author{
Jennifer S. Sobeck ${ }^{1}$, James E. Lawler ${ }^{2}$ and Christopher Sneden ${ }^{1}$
}

\begin{abstract}
Branching fraction measurements from Fourier transform spectra in conjunction with published radiative lifetimes are used to determine transition probabilities for 263 lines of neutral chromium. These laboratory values are employed to derive a new photospheric abundance for the Sun: $\log \epsilon(\mathrm{Cr} \mathrm{I})_{\odot}=5.64 \pm 0.01$ $(\sigma=0.07)$. These Cr I solar abundances do not exhibit any trends with line strength nor with excitation energy and there were no obvious indications of departures from LTE. In addition, oscillator strengths for singly-ionized chromium recently reported by the FERRUM Project are used to determine: $\log \epsilon(\mathrm{Cr} \text { II })_{\odot}$ $=5.77 \pm 0.03(\sigma=0.13)$. Transition probability data are also applied to the spectra of three stars: HD 75732 (metal-rich dwarf), HD 140283 (metal-poor subgiant), and CS 22892-052 (metal-poor giant). In all of the selected stars, Cr I is found to be underabundant with respect to $\mathrm{Cr}$ II. The possible causes for this abundance discrepancy and apparent ionization imbalance are discussed.
\end{abstract}

Subject headings: Galaxy: atomic data - stars: Population II-Sun: abundances: general - stars: abundances — stars: Population II

\section{INTRODUCTION}

Accurate abundances are a key component necessary to understand stellar chemical evolution. The derivation of reliable abundance values requires precise atomic data (i.e. radiative lifetimes, branching ratios, and transition probabilities). Early laboratory efforts to determine these atomic parameters began decades ago. Now with advances in astronomical instrumentation, the accuracy of the atomic parameters has become a main source of

\footnotetext{
${ }^{1}$ Department of Astronomy and McDonald Observatory, University of Texas, Austin, TX 78712; jsobeck@astro.as.utexas.edu,chris@verdi.as.utexas.edu

${ }^{2}$ Department of Physics, University of Wisconsin, Madison WI 53706; jelawler@wisc.edu
} 
uncertainty in the abundance determination. New investigations are underway which employ modern laboratory techniques to facilitate the extension and the improvement of these previous measurements of atomic data.

Chromium is a member of the iron peak group $(Z=24)$ with one dominant isotope $\left({ }^{52} \mathrm{Cr}\right)$. The synthesis of chromium is directly dependent on iron as the parent nucleus of ${ }^{52} \mathrm{Cr}$ is ${ }^{52} \mathrm{Fe}$ (e.g. Nakamura et al. 1999). Prior to the mid-90's, abundance surveys found $[\mathrm{Cr} / \mathrm{Fe}] \simeq 0$ for stars across the entire range of metallicity (e.g. Magain 1989, Ryan et al. 1991, Gratton \& Sneden 1991). Taking into consideration both the nucleosynthetic linkage and the observational data, $[\mathrm{Cr} / \mathrm{Fe}]$ was believed to remain at its solar ratio independent of metallicity. However McWilliam et al. (1995) examined abundances in a sample of extremely metal-poor stars, finding that $[\mathrm{Cr} / \mathrm{Fe}] \sim 0$ until approximately $[\mathrm{Fe} / \mathrm{H}]=-2.5$, and then starts to decrease steadily with $[\mathrm{Fe} / \mathrm{H}]$. Additional observations by Cayrel et al. (2004) and Aoki et al. (2005) supported this finding. Note that most of these abundance analyses employed only Cr I transitions.

The literature contains multiple studies of Cr oscillator strengths. The major investigations include those of Wujec \& Weniger (1981; Cr I/II), Tozzi et al. (1985; Cr I) and Blackwell et al. (1984a, 1986; Cr I). A new study of transition probabilities for singlyionized chromium from the FERRUM Project has recently been published (Nilsson et al. 2006). These Cr II results provided motivation for us to undertake a new study of Cr I oscillator strengths. Together, these two sets of high-quality transition probability data would allow for the accurate re-determination of the $\mathrm{Cr}$ abundance in the solar photosphere and examination of its ionization equilibrium.

In $\S 2$, we briefly summarize the radiative lifetimes employed in our work. $\S 3$ contains a description of our use of National Solar Observatory (NSO) digital archive spectra to measure Cr I branching fractions and a list of our new Cr I oscillator strengths. A report of our determinations of the Cr abundance in Sun and three other stars is found in $\S 4$, along with a discussion of the implications of our Cr abundance analysis.

\section{Radiative Lifetime Measurement Summary}

Cooper et al. (1997) reported radiative lifetime measurements for 131 levels of Cr I. They employed a time-resolved Laser Induced Fluorescence (LIF) technique on a slow atomic beam of $\mathrm{Cr}$ atoms from a hollow cathode discharge. Cooper et al. were attentive to possible systematic errors from: (1) electronic bandwidth, linearity, and fidelity limitations, (2) flight-out-of view effects, (3) radiation trapping, (4) collisional quenching, and (5) Zeeman 
quantum beats. Most importantly they re-measured certain "benchmark" lifetimes to check the accuracy of their apparatus during their work on $\mathrm{Cr}$ I. Table 1 is a list of radiative lifetimes from Cooper et al. for the 65 Cr I levels included in our branching fraction study.

The $\pm 5 \%$ accuracy claim of Cooper et al. (1997) may be verified by matching up their results to other (less extensive) Cr I LIF measurements. Specific comparisons of the average and the root mean square (RMS) differences between their lifetimes and other literature values are as follows: $+0.9 \%$ and $2.5 \%$ respectively for three levels in common with the study by Measures et al. (1977), $+8.5 \%$ and $9.0 \%$ respectively for six levels shared with the determination by Marek (1975), and $-2.0 \%$ and $5.1 \%$ respectively for twenty-three levels in common with the study of Kwiatkowski et al. (1981) 1 . The slightly larger discrepancy between the Cooper et al. lifetimes and those of Marek is not a concern as Marek claimed $8 \%$ uncertainty on his measurements. Two separate individual LIF lifetime measurements by Cooper et al. are in good agreement with values reported by Kwong \& Measures (1980) and Hannaford \& Lowe (1981). In addition, their results compare relatively well to measurements with non-LIF techniques. For example, six lifetimes determined by Marek and Richter (1973; phase-shift method) agree with the Cooper et al. measurements, as do six lifetimes measured by Becker et al. (1977; level-crossing technique).

The comparison to the National Institute of Standards and Technology (NIST) critical compilation (Martin et al. 1988) in Table 1 involved the summation over all of the Einstein A-coefficients for the transitions from the upper level. In some cases the sum is incomplete and only an upper limit can be determined. The NIST critical compilation included results from a variety of techniques. Although it is not expected to be as accurate as individual LIF measurements, the NIST compilation actually agrees well with the Cooper et al. results.

\section{Branching Fractions and Atomic Transition Probabilities}

It was our intention to record new spectra on a variety of Fe-group species during a Kitt Peak run in June 2005. Maintenance problems with the NSO $1.0 \mathrm{~m}$ Fourier Transform Spectrometer (FTS) prevented the acquisition of new data and led to an extended shutdown of this crucial FTS facility. Despite this setback, we were able to move forward and generate an expanded set of Cr I transition probabilities with existing FTS spectra.

The primary specifications of the FTS instrument are: (1) wavenumber accuracy of 1 part in $10^{8}$, (2) broad spectral coverage range from the UV to the IR, (3) optimal resolution

\footnotetext{
${ }^{1}$ The reference values for these differences are the Cooper et al. data.
} 
limit of $0.01 \mathrm{~cm}^{-1}$, and (4) spectrum recording capability of $10^{6}$ points in 10 minutes (Brault 1976). The FTS interferogram is a simultaneous measurement on spectral resolution elements from the UV to near IR. This gives the FTS an advantage over single-channel, sequentiallyscanned grating monochromators which are more vulnerable to branching fraction errors from drifts in source performance.

We performed a search of all spectra in the publicly-accessible digital archives of the NSO. Numerous chromium spectra were located, however based on various selection criteria (i.e. range of lamp currents and relatively low buffer gas pressures) only seven were deemed acceptable. General characteristics of the spectral data set include: hollow cathode discharge (HCD) lamp sources with fused silica windows, argon or neon fills, interferograms with multiple co-adds, applied currents in the range 0.1-1.5 A, and buffer gas pressures in the range of 0.65-4.00 Torr. Details regarding the chosen spectra may be found in Table 2. The majority of spectra were recorded at high discharge currents. Though high current spectra yield good S/N measurements of weak lines, radiation trapping or optical depth effects arise. For instance, spectra 3-5 have serious problems of this sort even for emission lines terminating on Cr levels with $1 \mathrm{eV}$ excitation potentials. Spectrum 6, although not the lowest current spectrum, has minimal optical depth problems for $\mathrm{Cr}$ I lines to the $1 \mathrm{eV}$ lower levels. In order to resolve these optical depth problems and to improve the radiometric calibration in the near IR, we made some additional laboratory measurements with a grating spectrometer which will be described in $\S 3.1$.

Essential to the branching ratio measurement is the accurate determination of the relative radiometric calibration or efficiency of the FTS. In effect, the radiometric efficiency is the quantification of the FTS instrument response. A methodology to arrive at a radiometric calibration has been established by Adams \& Whaling (1981) which involves the use of selected sets of Ar I and Ar II lines in the range 4300-35,000 $\mathrm{cm}^{-1}$. Confirmation and refinement of these lists of Ar I and Ar II branching ratios have subsequently been done by Danzmann \& Kock (1982), Hashiguchi \& Hasikuni (1985) and Whaling et al. (1993). The apparent intensity of subsets of Ar I and Ar II lines from a common upper level divided by the branching ratios of these lines is used to determine the FTS radiometric efficiency as a function of wavenumber. The radiometric calibration includes efficiency variations as a function of wavenumber from the optical components of the FTS and lamp system. Calibrations based solely on the Ar line technique were used for spectra 1, 2, and 6. Spectra of the Kitt Peak Optronics 15 A tungsten strip lamp were recorded during the 1984 run shortly before and after the Cr-Ne hollow cathode lamp spectra. This tungsten filament lamp is a secondary standard with a known spectral radiance and its spectra were used to establish a relative radiometric calibration of $\mathrm{Cr}-\mathrm{Ne}$ spectra 3, 4, and 5 from 1984. A spectrum of a 6.25 A tungsten filament lamp from March 25, 1980 was used to smooth the Ar line cali- 
bration of spectrum 7 from the same date. We do not have access to the calibration curve for this standard lamp, but we were able to reconstruct a calibration using other archived FTS data from the same period. Note that tungsten filament lamp calibrations are most useful near the decline in FTS sensitivity at $12,500 \mathrm{~cm}^{-1}$ (attributed to the aluminum mirror coatings), and between 10,000 and $8,000 \mathrm{~cm}^{-1}$, where the response of the silicon detector rapidly diminishes.

All possible transition wavenumbers between the known energy levels of Cr I satisfying both the parity change and $\Delta J=0, \pm 1$ selection rules were computed and used during the analysis of the FTS data. Energy Levels from Sugar \& Corliss (1985) were used to determine all possible transition wavenumbers. Spectral features at these wavenumbers were numerically integrated to determine apparent line intensities that are subsequently divided by the relative radiometric calibration to yield branching ratios.

The procedure for determining branching fraction uncertainties has been extensively described in Wickliffe et al. (2000). Branching fractions from a given upper level are defined to sum to unity, thus a dominant line from an upper level has small branching fraction uncertainty almost by definition. Branching fractions for weaker lines near the dominant line(s) tend to have uncertainties limited by their signal-to-noise ratios. Systematic uncertainties in the radiometric calibration are typically the most serious source of uncertainty for widely-spaced lines from a common upper level.

Branching fraction measurements were completed on 65 of the 131 levels from the lifetime experiment. Some of the levels for which branching fractions could not be obtained have significant branches which fall outside the spectral coverage region of the FTS configuration. The division of the branching fractions by the radiative lifetimes results in the transition probabilities for chromium lines. Table 3 presents oscillator strengths for 263 transitions of $\mathrm{Cr}$ I. Note that the table omits transition probability data for a few weak lines from selected upper levels. These omissions are due to excessively large uncertainties from low $\mathrm{S} / \mathrm{N}$, blending issues, and some calibration problems for weak lines widely separated from dominant branches connected to the same upper level. Branching fractions of strong lines were corrected using our rough measurements on the omitted weak lines. Inaccuracies in the branching fractions of the weak lines have negligible effect on the accuracy of the branching fractions for the strong lines. The branching fraction uncertainty was combined in quadrature with the radiative lifetime uncertainty to yield the transition probability uncertainty shown in Table 3. 


\subsection{Grating Spectrometer Measurements}

Supplemental measurements were made using a $0.5 \mathrm{~m}$ focal length grating spectrometer equipped with a set of dye and interference filters and a diode detector array. The purpose of these supplemental measurements was to verify and improve the IR radiometric calibration of the primary FTS data as well as further investigate the optical depth problems in a small portion of this data. We used small, sealed $\mathrm{Cr}-\mathrm{Ne}$ and $\mathrm{Cr}-\mathrm{Ar}$ hollow cathode lamps, which are standardly found in atomic absorption spectrophotometers. To eliminate optical depth concerns during these measurements, the operational discharge current was limited to a range of 1.0-4.0 mA. Two diffraction gratings were used: a first-order 1200 groove $/ \mathrm{mm}$ grating for broad coverage in a single exposure and an echelle grating with 316 groove $/ \mathrm{mm}$ and a 63 degree blaze for high spectral resolution. A tungsten-quartz-halogen lamp was employed to calibrate the radiometric response of the spectrometer system (which included filters used to suppress scattered radiation). Special attention was devoted to optical depth effects in the $\mathrm{z}^{5} \mathrm{P}$ to $\mathrm{a}^{5} \mathrm{~S}$ and $\mathrm{z}^{5} \mathrm{P}$ to $\mathrm{a}^{5} \mathrm{D}$ multiplets. In the solar $\mathrm{Cr}$ abundance determination of Blackwell et al. (1987), these multiplets were specifically mentioned and will be discussed in further detail in $§ 4.4$.

Spot checks with the grating spectrometer were performed on the the longest wavelength $\mathrm{z}^{5} \mathrm{~F}$ to $\mathrm{a}^{5} \mathrm{G}$ multiplets. These re-measurements indicated that in the IR, FTS data calibrated with the Optronic 15 A tungsten strip lamp were more accurate than those calibrated with the Ar I/II line method. This is in part due to the weakness of the Ar I lines at high discharge currents. However, the overwhelming majority of final transition probabilities listed in Table 3 are derived from FTS spectra.

\subsection{Theoretical Transition Probabilities}

Some of the high spin levels of transition metals such as Cr display relatively pure LS or Russell-Saunders coupling. We have used the standard LS formulae from Condon \& Shortley (1935) with a frequency cubed correction to compute transition probabilities for selected multiplets in Table 3. The absolute scale of the transition probabilities of each multiplet was normalized to match one line in the multiplet. The lines used for these normalizations are labeled with a "N" in Table 3. As shown, the A-values from LS-coupling computations agree well with those from experiment (where the average and rms values of $\left(A_{E x p}-A_{L S c a l c}\right) / A_{E x p}$ are found to be 0.011 and 0.084 respectively). 


\subsection{Comparison to Previous Studies}

Numerous investigations of oscillator strengths for neutral chromium have been made with a variety of techniques. Significant experimental initiatives in this vein include the pioneering work of Corliss \& Bozmann (1962), the shock tube approach of Wolnik et al. (1968, 1969), and the arc emission method of Wujec \& Weniger (1981). Theoretical determinations of Cr I transition probabilities have been done by Biémont (1974) and Kurucz \& Peytremann (1975). Here, we focus on comparisons with two more recent sets of measurements: the hook and emission method of Tozzi et al. (1985) and the furnace absorption technique of Blackwell et al. (1984a, 1986). We also comment on the relationship of our gf data to those of the NIST critical compilation.

Oscillator strengths for $60 \mathrm{Cr}$ I lines (which originate from 14 different upper levels) were reported by Tozzi et al. (1985). Measurements of branching fractions were done with the hook and emission method. The Tozzi et al. branching fractions were combined with the radiative lifetimes from Kwiatkowski et al. (1981) to yield the gf values with an internal accuracy of $7 \%$. Figure 1 shows the differences between the log gf values from Tozzi et al. (1985) and those from our work, as a function of wavelength, transition probability, and upper level transition energy. Overall, the agreement between their values and ours is quite good. A minor trend in wavelength is seen in the upper panel of Figure 1, the agreement between the two data sets worsens as wavelength increases. The lower panel of Figure 1 displays a similar trend with $\mathrm{E}_{\text {upper }}$. We have 41 transitions in common with Tozzi et al. with the average and rms values of $\log (g f)_{\text {Tozzi }}-\log (g f)_{\text {Sobeck }}$ calculated to be -0.01 and 0.04 respectively.

With the use of the furnace absorption technique, the Blackwell group published two papers (1984a, 1986) on Cr I oscillator strengths. The yield of the two efforts was $102 \mathrm{Cr}$ I oscillator strengths from 38 different upper levels with an internal accuracy claim of better than 1\%. Figure 2 displays a comparison of our gf data to that of Blackwell et al. There is excellent agreement between the 57 lines that we have in common. The average and rms values of $\log (g f)_{\text {Blackwell }}-\log (g f)_{\text {Sobeck }}$ are found to be -0.01 and 0.04 respectively.

NIST has assembled a collection of Cr I transition probability data from 11 different sources (Martin et al. 1988). Classification of oscillator strengths in terms of accuracy is done by NIST as follows: $A \leq 3 \%, B \leq 10 \%, C \leq 25 \%, D \leq 50 \%$, and $E>50 \%$. Figure 3 presents our data in comparison to the NIST compilation. We share 155 transitions with the NIST compilation with the average and rms values of $\log (g f)_{N I S T}-\log (g f)_{\text {Sobeck }}$ tabulated to be +0.05 and 0.12 respectively. A specific breakdown of the average and rms differences of $\log (g f)_{\text {NIST }}-\log (g f)_{\text {Sobeck }}$ with respect to the NIST oscillator strength categorization is as follows: B-level, -0.01 and 0.033 respectively; C-level: 0.10 and 0.13 respectively; D- 
level, 0.08 and 0.17 respectively; and E-level 0.17 and 0.17 respectively. The upper panel of Figure 3 shows a systematic trend with wavelength (as the wavelength decreases, the mean agreement between the two data sets diminishes and the line-to-line scatter increases). We have gf data for 2 E-level and 49 D-level accuracy transitions which should be taken as an improvement and given preference over the NIST values.

\section{Solar and Stellar Chromium Abundances}

Our new Cr I oscillator strength data are now applied to the solar spectrum and a few other stars. We have chosen stars of varying metallicity and evolutionary state: HD $75732([\mathrm{Fe} / \mathrm{H}]=+0.35$; an extremely metal-rich dwarf $) ; \mathrm{HD} 140283([\mathrm{Fe} / \mathrm{H}]=-2.50$; a very metal-poor subgiant); and CS 22892-052 $([\mathrm{Fe} / \mathrm{H}]=-3.10$; a well-characterized, low metallicity, r-process rich giant). Our Cr abundance analysis was facilitated by the existence of numerous transitions in the visible wavelength range and the presence of both the neutral and first-ionized species.

\subsection{Inclusion of Oscillator Strengths for Singly-Ionized Chromium from the FERRUM Project}

The availability of new Cr II transition probabilities (Nilsson et al. 2006) enables us to compare the solar abundance value from the Cr I lines to that from the Cr II lines. Nilsson et al. (2006) and our group both employ the same technique which is the mostadvanced and broadly applicable for determining transition probabilities in complex spectra. With the combination of LIF radiative lifetime determinations and FTS branching fraction measurements, they have generated a complete set of gf values for the 25 lowest odd-parity energy levels of Cr II. Nilsson et al. give oscillator strengths for $119 \mathrm{Cr}$ II transitions in the wavelength range 2050-4850 $\AA$ with an uncertainty of $\sim 10-15 \%$.

\subsection{Line Selection and Analysis}

Development of a line list suitable for stellar abundance analysis involved two selection criteria: detection of blends and determination of relative line strength. To review the numerous available chromium transitions, we employed the solar spectral identification atlas of Moore et al. (1966) and the atomic line and parameter compendium VALD (Vienna Atomic Line Database, Kupka et al. 1999). We eliminated all lines with strong core blends 
and those with significant wing contaminants (within $0.1 \AA$ of the transition center). As a result, a significant number of lines (slightly less than $40 \%$ of the initial list) still remain at hand for abundance determinations.

Equivalent width analyses were sufficient to determine the elemental abundance of chromium as effects due to hyperfine and isotopic splitting were negligible. Chromium has three stable isotopes: ${ }^{52} \mathrm{Cr}(83.79 \%),{ }^{53} \mathrm{Cr}(9.50 \%)$, and ${ }^{54} \mathrm{Cr}(2.37 \%)$. A fourth isotope. ${ }^{50} \mathrm{Cr}$ $(4.36 \%)$, is metastable with an extremely long half-life $(\tau>1.8 E 17$ years $)$. The odd isotope ${ }^{53} \mathrm{Cr}$ does not posses significant hyperfine structure as its nuclear g-factor is small (the dipole moment is -0.47 nuclear magnetons with $I=3 / 2$ ). The isotopic splitting of $\mathrm{Cr}$ lines is imperceptible (shifts are less than $0.007 \AA$, Heilig \& Wendlandt 1967) and consequently, do not contribute to changes in abundance.

To measure the equivalent widths (EWs), we used the interactive software package SPECTRE of Fitzpatrick \& Sneden (1987). For a particular transition, the numerical evaluation of the equivalent width was done via the fit of a Gaussian to the line profile. We did not find any evidence of excessive damping in the wings of strong lines. A few synthetic spectrum computations were done as spot-checks and no appreciable gain in accuracy was found. Table 4 lists the EW values for all target stars.

To gauge line strengths, we employed reduced widths, defined as $R W=E W / \lambda$. The evaluation of $\log (\mathrm{RW})$ for an individual line determines its position on the curve of growth (COG). Line saturation of (some) Cr I and Cr II transitions is an issue and must be dealt with accordingly. In the case of the Sun, transitions with a $\log (\mathrm{RW})>-4.3$ were found to lie on the exponential portion of the COG (consequently, insensitive to changes in abundance) and were immediately discarded.

For an individual specie, the determination of stellar abundances under the stipulation of LTE allows for the relation of line strengths to both transition probabilities and BoltzmannSaha factors. We may define a relative strength factor (RSF) as log $g f-\theta \chi$ where $\chi$ is the excitation energy in units of $\mathrm{eV}$ and $\theta$ is the standard inverse temperature relation, $\theta=5040 / T$. Consequently for weak lines, $\log (\mathrm{RW})$ is directly proportional to the RSF. Figure 4 shows our computation of the RSF for neutral chromium lines in the Sun (in which case $\theta$ becomes 0.87 ). Notice that the $5844.59 \AA$ line with an extremely low RSF of -6.19 is still detectable in the Sun and that the strongest transitions are located in the ultraviolet and blue visible portions of the spectrum.

With the aid of energy level information from the NIST database, the re-computation 
of the partition functions for both $\mathrm{Cr}$ I and Cr II was done.2 These data were then compared to the partition functions from Irwin (1981) and to those from Halenka \& Grabowski (1986). Good agreement among the data sets was established and the newly computed partition functions for Cr II were used in the abundance determination.

\subsection{The Solar Photospheric Chromium Abundance}

For cooler stars, main sequence stars (of high surface gravity) such as the Sun, collisional line broadening must be taken into account. In these types of stellar atmospheres, the broadening of strong spectral features is predominantly due to collisions with neutral hydrogen atoms. The classical treatment of collisional broadening involves van der Waals theory and the determination of the interaction energy parameter. In the Unsold approximation $(1927,1955)$, the interaction energy is related to the fixed energy debt, $\mathrm{E}_{p}$, which is set to $\mathrm{E}_{p}=4 / 9 \mathrm{AU}$ for all atoms regardless of species (note that from this $\mathrm{E}_{p}$, the familiar van der Waals damping coefficient, $\mathrm{C}_{6}$ is obtained). An improved approach (applicable to both neutral and ionized species) was developed by Anstee, Barklem, \& O'Mara (hereafter labeled ABO theory; Barklem \& Aspelund-Johasnsson 2005; Barklem et al. 1998 and references therein). Essentially, it derives the interaction energy via the analytical determination to within a single numerical integration over the radial wavefunction of the perturbed atom (O’Mara \& Barklem 2003). ABO theory calculations have been done for tens of thousands of lines in the wavelength range $2300-13000 \AA$ of elements Li to Ni with a maximum error of about 20\% (Barklem \& Aspelund-Johansson 2005; Barklem et al. 2000). We made use of the publicly available collision damping constants (through the VALD catalog) and requested new calculations for those Cr I and Cr II transitions without published values (P. Barklem, priv. comm.).

The current version of the LTE line analysis code MOOG (Sneden 1973) was employed to calculate the abundances. Our source of observed solar photospheric spectra was the center-of-disk spectral atlas of Delbouille et al. (1973). Initially, we selected a Holweger \& Müller (1974) model with a microturbulent velocity of $\mathrm{v}_{\mathrm{t}}=0.80 \mathrm{~km} \mathrm{~s}^{-1}$. Other model types we then tried include: MARCS (Gustaffson et al. 1975), ATLAS (Kurucz 1993), Grevesse \& Sauval (1999), newMARCS (Gustaffson et al. 2003), and Asplund et al. (2004). Table 5 lists the abundance data from the various models. We adopted the Holweger-Müller model

as it resulted in the smallest Cr I/II abundance difference as well as the lowest internal line scatter. The mean solar photospheric abundance for 58 lines of $\mathrm{Cr}$ I is $\log \epsilon(C r)=5.64 \pm 0.01$

\footnotetext{
${ }^{2}$ The relevant NIST website is: http://physics.nist.gov/PhysRefData/ASD/levels_form.html.
} 
$(\sigma=0.07)$ and 10 lines of Cr II is $\log \epsilon(C r)=5.77 \pm 0.03(\sigma=0.13)$.

Figure 5 demonstrates that Cr I abundances do not exhibit any trends with equivalent width, excitation potential, or wavelength. In this figure, we have encircled the two most anomalous data points at $3018.49 \AA$ and $4646.15 \AA$. Spectral line synthesis of these two transitions did not significantly change their respective abundance values. The presence of unknown blends and the continuum determination are most certainly issues for the 3018.49 $\AA$ line. As for the feature at $4646.15 \AA$ we detect a slight line asymmetry, however we are not able to identify the exact cause for its aberrant abundance (as the line originates from a dominant branch, has a highly accurate transition probability, and possesses no strong contaminants). The result of the exclusion of these two transitions from the abundance determination is $\log \epsilon(\mathrm{Cr})=5.64 \pm 0.01$ with $\sigma=0.05$ (a slight decrease in the standard deviation).

For error estimation, we consider the dependence of the chromium abundances on stellar atmospheric parameters and damping constants. If we vary the $\mathrm{v}_{\mathrm{t}}$ by $+0.2 /-0.2 \mathrm{~km} \mathrm{~s}^{-1}$, we find that the Cr I abundance changes by $-0.04 /+0.03$ dex and the Cr II abundance by $-0.07 /+0.06$ dex. An alteration in $\mathrm{T}_{\text {eff }}$ of $+100 /-100 \mathrm{~K}$ results in abundance changes in $\mathrm{Cr} \mathrm{I}$ and $\mathrm{Cr}$ II of $+0.08 /-0.07$ dex and $+0.00 /-0.00$ dex respectively. A surface gravity variation of $\Delta \log g=+0.20 /-0.20$ yields a $-0.02 / 0.0$ dex Cr I abundance change and a $+0.03 /-0.04$ dex Cr II abundance change. If we then employ a damping constant formulation as suggested by Blackwell et al. (1984b; also mentioned in Simmons \& Blackwell 1982) as opposed to the Barklem values, our Cr I abundance decreases just slightly by 0.02 dex to $5.62 \pm 0.01$ and our Cr II abundance becomes $5.74 \pm 0.03$ (0.03 dex decrease). It is apparent that the singly-ionized chromium abundance is more sensitive to these parameter adjustments (in the solar photosphere, Cr II is the dominant species as chromium has a relatively small first-ionization potential, $6.766 \mathrm{eV}$ Grigoriev \& Meilikhov 1997). For stars with atmospheric parameters similar to the Sun, the total systematic error of the abundance values is estimated to be 0.09 dex for both Cr I (largely attributed to uncertainty in $\mathrm{T}_{\text {eff }}$ ) and Cr II (mostly due to uncertainty in $\mathrm{v}_{\mathrm{t}}$ ).

One of the first studies to have had the benefit of both high quality spectra and transition probability data, Biémont et al. (1978) derived $5.64 \pm 0.10$ for the solar photospheric chromium abundance. The critical compilation of solar system abundances by Anders \& Grevesse (1989) recommends $\log \epsilon(\mathrm{CrI})_{\odot}=5.67 \pm 0.03$ (subsequent publications, Grevesse et al. 1996 and Grevesse \& Sauval 1998, restate this value). Asplund et al. (2005a find $\log \epsilon(\mathrm{CrI})_{\odot}=5.64 \pm 0.10$. All of these numbers are in excellent agreement with the current meteoritic value of $5.63 \pm 0.05$ (Lodders 2003). None of the solar abundance determinations use lines from singly-ionized chromium. With 58 transitions, we have been able to derive a 
value for the solar abundance of neutral chromium, $5.64 \pm 0.01$, which is in good agreement with these values from literature.

\subsection{Detection of non-LTE Effects in Excitation for Neutral Chromium?}

Blackwell et al. (1987) reported indications of non-LTE effects in excitation for lines of neutral chromium. The abundance derivation procedure of the Blackwell group is summarized as follows: use of the solar photospheric spectral atlas by Delbouille et al. (1973); determination of collisional damping constants; employment of both the Holweger-Müller (1974) and MARCS (Gustaffson et al. 1975) model atmospheres; and EW measurement via a synthetic line profile fit to an observed transition. In contrast to the $\mathrm{Cr}$ I lines of higher excitation potential, they found a noticeably larger spread in the abundances from the 1 $\mathrm{eV}$ lines. Particularly for three transitions of the $\mathrm{z}^{5} \mathrm{P}$ multiplet $(5247.57 \AA, 5300.75 \AA$, and $5345.80 \AA)$, Blackwell et al. reported a markedly higher abundance $\left(<\log \epsilon_{C r I-z^{5} P}\right\rangle=5.81$ as opposed to $\left\langle\log \epsilon_{C r I}>=5.69\right.$ ). They did not consider that the oscillator strengths of these $1 \mathrm{eV}$ lines as sources of major error since they agreed well with those gf values given by Tozzi et al. (1985). Nor did they believe the equivalent widths were at fault (in the case of the $\mathrm{z}^{5} \mathrm{P}$ multiplet) as Blackwell et al. were not able to detect any blends. On the basis of these two pieces of evidence, the Blackwell group concluded that non-LTE did indeed affect these Cr I lines.

In the present study, we re-examine these low excitation chromium transitions. We do not find an abnormally large scatter in the abundances of the $1 \mathrm{eV}$ lines (in fact, the standard deviation for these lines was $\sigma=0.06$; exactly the same as that for the entire line list). Also, the three transitions of the $\mathrm{z}^{5} \mathrm{P}$ multiplet do not appear to give an anomalously high abundance $\left(\log \epsilon_{C r I-z^{5} P}=5.65\right.$ as compared to $\left.<\log \epsilon_{C r I}>=5.64\right)$. In addition to these three lines, we derive the abundances for 3 more transitions of the $\mathrm{z}^{5} \mathrm{P}$ multiplet with the average for all lines equal to 5.70. Table 6 displays all of the results and shows that our transition probabilities for these lines agree very well with those of Blackwell et al. This table also shows a comparison of three sets of EW measurements. We see that our values agree very well with those of Moore et al. (1966) whereas the Blackwell EWs report consistently higher than ours. We are not able to pinpoint the exact reasons for the discrepancy between the Blackwell et al. data and our own for these $\mathrm{z}^{5} \mathrm{P}$ transitions. In summary, we do not find any compelling evidence for departures from LTE in the transitions of Cr I. 


\subsection{Chromium Abundances in Other Stars}

We now consider how the new Cr I and Cr II transition probability data affects the $[\mathrm{Cr} / \mathrm{Fe}]$ ratios in other stars. In a preliminary investigation, we have derived new values in three stars with previously established chromium abundances. These stars represent extremes in metallicity and exhibit different evolutionary states. We modified the initial line list to account for the unique blending and detectability concerns of each star and performed EW measurements. Table 4 gives the EW data for all of the stars. We used an interpolation software program (kindly provided by I. Ivans and A. McWilliam) to generate model atmospheres from the ATLAS grid (Kurucz 1993). We then proceeded with abundance determinations in the manner described above.

HD 75732 ( $\rho^{1}$ Cnc) is a metal-rich disk main sequence star which is host to a planetary system that was first detected by Butler et al. (1997). The most recent publication of chromium abundances for this star is from the large survey by Luck \& Heiter (2005). We adopted the model atmosphere parameters for HD 75732 as reported by Valenti \& Fischer (2005): $\left(T_{\text {eff }} / \log g /[\mathrm{Fe} / \mathrm{H}]\right)=(5235 / 4.45 /+0.25)$ which differ from those listed by Luck \& Heiter: $\left(T_{\text {eff }} / \log g /[\mathrm{Fe} / \mathrm{H}] / v_{t}\right)=(5375 / 4.35 /+0.50 / 0.45)$. We derived abundances of $\log \epsilon(\mathrm{Cr} \mathrm{I})=5.98(\sigma=0.12,31$ lines $)$ and $\log \epsilon(\mathrm{Cr}$ II $)=6.22(\sigma=0.05,3$ lines $)$. The Luck $\&$ Heiter $(2005)$ values for this star $\log \epsilon(C r I)=6.15(\sigma=0.14)$ and $\log \epsilon(C r I I)=6.25$ $(\sigma=0.12)$ are comparable to ours (the difference between the values falls within the stated uncertainties). The discordance between the abundances from $\mathrm{Cr}$ I and $\mathrm{Cr}$ II lines for HD 75732 is 0.24 dex. With the use of the $\S 4.3$ solar abundances, we find that $[\mathrm{Cr} / \mathrm{H}]_{\mathrm{I}}=+0.34$ and $[\mathrm{Cr} / \mathrm{H}]_{\mathrm{II}}=+0.45$ (which further confirms the super-metal-rich status of this star).

The subgiant HD 140283 was one of the first very metal-poor stars to be discovered (Chamberlain \& Aller 1951) and has been well-studied over the past several decades. The Cr I abundance for this star was reported by King et al. (1998): $\log \epsilon(\mathrm{Cr} I)=2.85(\sigma=0.10)$. With the model atmospheric parameters suggested by I. Ivans (5725/3.65/-2.20/1.10; 2006 priv.comm.), we obtained $\log \epsilon(\mathrm{Cr} \mathrm{I})=2.86(\sigma=0.04,13$ lines $)$ and $\log \epsilon(\mathrm{Cr}$ II $)=3.16$ ( $\sigma=0.14,11$ lines). The King et al. value agrees well with ours though it is based on a single line. For HD 140283, we also determined the differential abundances $[\mathrm{Cr} / \mathrm{H}]_{\mathrm{I}}=-2.83$ and $[\mathrm{Cr} / \mathrm{H}]_{\mathrm{II}}=-2.65$.

Sneden et al. (1994, 2003) detected a significant enhancement of $r$-process neutroncapture elements in the very metal-poor giant CS 22892-052. They were also able to determine the chromium abundances for this star: $\log \epsilon(\mathrm{Cr} \mathrm{I})=2.33(\sigma=0.11,6$ lines $)$ and $\log \epsilon(\mathrm{Cr}$ II $)=2.42(\sigma=0.14,2$ lines $)$. The model atmospheric parameters $(4800 / 1.50 /-$ $3.12 / 1.95)$ from Sneden et al. 2003 were used to derive: $\log \epsilon(\mathrm{Cr} \mathrm{I})=2.31(\sigma=0.13,9$ lines) and $\log \epsilon(\mathrm{Cr}$ II $)=2.54(\sigma=0.13,7$ lines $)$. Our values agree reasonably well with 
those reported by Sneden et al (and we believe supersede them). In addition, we find for CS 22892-052 the differential abundances: $[\mathrm{Cr} / \mathrm{H}]_{\mathrm{I}}=-3.33$ and $[\mathrm{Cr} / \mathrm{H}]_{\mathrm{II}}=-3.23$.

These data offer a brief snapshot of the chromium abundance trend with metallicity in the Galaxy. They suggest that the disagreement in abundance values from Cr I and Cr II widens as the metallicity decreases (the derivation of Fe abundances and subsequent $[\mathrm{Cr} / \mathrm{Fe}]$ determination awaits an investigation with a larger available data pool analyzed in a consistent manner). The difference appears to grow from $\simeq-0.1$ at $[\mathrm{Fe} / \mathrm{H}]>0$ to perhaps as much as $\simeq-0.3$ at $[\mathrm{Fe} / \mathrm{H}]<-2.5$ (though the effect is substantially lessened if the solar abundance discrepancy between the two species is acknowledged). Finally, we emphasize that the chosen model parameters are taken from the literature, and these choices impact the derived abundances.

\subsection{Chromium Ionization Imbalance Result of Departures from LTE?}

We have shown that factors such as model grid selection, stellar atmospheric parameter choice, and equivalent width measurement technique cannot fully account for the sizable abundance discrepancy between the Cr I and Cr II lines (which was detected in all stars). In the case of the Sun, the difference between $\log \epsilon_{C r I}=5.64(\sigma=0.07)$ and $\log \epsilon_{C r I I}=5.77$ ( $\sigma=0.13)$ is $\Delta=0.13$. We note though that this difference does fall within the error of $\sigma=0.15$ (by the quadrature addition of sigmas).

The inability to reconcile the abundances from the neutral and first-ionized states of a particular species is not unique. Even with the reference element Fe there are difficulties: the solar abundances from Fe I and Fe II transitions are likewise discordant. In the 1990's, multiple papers quoted different values for the photospheric abundance of Fe I and Fe II (e.g. Milford et al. 1994; Blackwell et al. 1995; Holweger et al. 1995; Anstee et al. 1997; and Schnabel et al. 1999). We are not aware of a study that simultaneously examines both Fe I and Fe II with atomic data obtained from one, sole laboratory technique and with abundances derived from a single, consistent methodology.

For every element, accurate determinations of the oscillator strengths for the majority ionic species is critical. Numerous challenges face laboratory spectroscopists. Large wavelength separations between dominant UV branches $(2000 \AA$ to $3000 \AA)$ and minor IR branches $(7000 \AA$ to $10000 \AA)$ from the same upper level hinder the radiometric calibration process (the frequency cubed scaling of the A values means for instance that a 2500

$\AA$ branch is $27 \times$ stronger than $7500 \AA$ branch with a similar dipole matrix element from the same upper level). For the dominant UV branches, the uncertainty depends upon the 
lifetime measurement. However, it is rarely useful to obtain abundances from these branches as they generally correspond to highly-saturated transitions. On the other hand for the weak IR branches, the uncertainty limitation is the branching fractions (as by definition they must sum to 1.0). Errors may also result from optical depth effects. The possibility exists for the weaker branches to drop into the noise before the discharge current is low enough to ensure that the dominant UV branches are optically thin.

In spite of these cautions, we do not believe that the transition probabilities are a significant error source. We took all possible steps to ensure the rigorous determination of the Cr I gf-values. The Cr II oscillator strengths from the FERRUM Project (Nilsson et al. 2006) are of the highest quality ("state-of-the-art" techniques were employed). They took steps to avoid optical depth effects. Furthermore, the Cr I/Cr II abundance disagreement is not consistent with optical depth problems in the Cr II branching fraction study. Note that the Nilsson et al. branching fractions compare well with those generated by the Cowan code (1981). Figure [6 displays the branching fractions associated with the $\mathrm{Cr}$ I and Cr II transitions used in the solar abundance analysis. As shown, only the weak branches of Cr II (with inherent errors in their associated A values of 9-37\%) were employed.

Given that the average abundance from Cr I lines is markedly lower than that from $\mathrm{Cr}$ II lines and the ostensible reliability of the oscillator strengths, we should now consider other possible causes with special focus on departures from LTE. Unfortunately, we have not been able to locate any published set of non-LTE calculations for Cr. Eventually, non-LTE effects will be quantified for a variety of elements (Asplund et al. 2005b and references therein). It is reasonable to expect that the non-LTE effects on the ionization balance will be larger than non-LTE effects on level populations in a single ionization stage. Estimations of the non-LTE influence on the solar photospheric abundances of some elements have been done by several groups. For example, Shchukina \& Trujillo (2001) suggest that non-LTE effects for Fe I lines might be as large as 0.1 dex. Future work on chromium should include (for instance) the precise re-measurement of the minor Cr II branches and the commencement of statistical equilibrium calculations.

\section{Conclusion}

Published lifetimes combined with branching fractions measured with Fourier transform spectrometry to determine transition probabilities for 263 lines of Cr I. This improved set of oscillator strengths has been used to determine the solar photospheric abundance of Cr I, $\log \epsilon=5.64 \pm 0.01(\sigma=0.07)$, from 58 lines. The spectra of three other stars (HD 140283, CS 22892-052, and HD 75732) was analyzed, employing 9 to 31 Cr I lines per star. 
With the use of plane-parallel models and the assumption of LTE conditions, we were not able to achieve ionization equilibrium in chromium. Abundances from Cr I transitions were consistently underabundant with respect to those from $\mathrm{Cr}$ II lines. We have speculated as to the possible causes of the discrepancy. Contributions from internal and external error sources cannot account for the difference. We note that the suppression of the Cr I abundance relative to that of $\mathrm{Cr}$ II is commensurate with the idea of $\mathrm{Cr}$ I overionization. Therefore, we believe that the discrepancy may be due to non-LTE effects. Our contention is not novel in that several other groups have suggested that departures from LTE effect element abundances in the Sun (e.g. Shchukina \& Trujillo Beno 2001, Takeda et al. 2005).

Steps toward the resolution of the chromium ionization imbalance problem include the re-measurement of the Cr II branching fractions and the reanalysis of the Cr abundance with a 3-dimensional hydrodynamical model.

We thank Inese Ivans for the use of her Keck I HIRES HD 140283 spectra and Carlos Allende Prieto for the use of his HD 75723 spectra (from his $\mathrm{S}^{4} \mathrm{~N}$ solar neighborhood stars database). We are deeply indebted to Paul Barklem for providing Cr I and Cr II damping constants. We are grateful to the NSF through grants AST 05-06324 to J. L. and AST 03-07495 to C. S. for providing funding support for this research. 


\section{REFERENCES}

Adams, D. L., \& Whaling, W. 1981, J. Opt. Soc. Am., 71, 1036

Anders, E., \& Grevesse, N. 1989, Geochim. Cosmochim. Acta, 53, 197

Anstee, S. D., O’Mara, B. J., \& Ross, J. E. 1997, MNRAS, 284, 202

Aoki, W., Honda, S., Beers, T. C., Kajino, T., Ando, H., Norris, J. E., Ryan, S. G., Izumiura, H., Sadakane, K., \& Takada-Hidai, M. 2005, ApJ, 632, 611

Asplund, M., Grevesse, N., Sauval, A. J., Allende Prieto, C., \& Kiselman, D. 2004, A\&A, 417,751

Asplund, M., Grevesse, N., \& Sauval, A. J. 2005a, ASPC, 336, 25

Asplund, M. 2005b, ARA\&A, 43, 481

Barklem, P. S., Anstee, S. D., \& O'Mara, B. J. 1998, PASA, 15, 336

Barklem, P. S., Piskunov, N., \& O’Mara, B. J. 2000, A\&AS, 142, 467

Barklem, P. S., \& Aspelund-Johansson, J. 2005, A\&A, 435, 373

Becker, U., Bucka, H., \& Schmidt, A. 1977, A\&A, 59, 145

Biemont, E. 1974, Sol. Phys., 38, 15

Biemont, E., Grevesse, N., \& Huber, M. C. E. 1978, A\&A, 67, 87

Blackwell, D. E., Menon, S. L. R., \& Petford, A. D. 1984a, MNRAS, 207, 533

Blackwell, D. E., Booth, A. J., \& Petford, A. D. 1984b, A\&A, 132, 236

Blackwell, D. E., Booth, A. J., Menon, S. L. R., \& Petford, A. D. 1986, MNRAS, 220, 303

Blackwell, D. E., Booth, A. J., Menon, S. L. R, \& Petford, A. D. 1987, A\&A, 180, 229

Blackwell, D. E., Lynas-Gray, A. E., \& Smith, G. 1995, A\&A, 296, 217

Brault, J. W. 1976, J. Opt. Soc. Am., 66, 1081

Butler, R. P., Marcy, G. W., Williams, E., Hauser, H., \& Shirts, P. 1997, ApJ, 474, 115

Cayrel, R., Depagne, E., Spite, M., Hill, V., Spite, F., Francois, P., Plez, B., Beers, T., Primas, F., Andersen, J., Barbuy, B., Bonifacio, P., Molaro, P., \& Nordstrom, B. 2004, A\&A, 416, 1117 
Chamberlain, J. W., \& Aller, L. H. 1951, ApJ, 114, 52

Condon, E. U., \& Shortley, G. H. 1935, The Theory of Atomic Spectra, Cambridge University Press, Cambridge

Cooper, J. C., Gibson, N. D., \& Lawler, J. E. 1997, J. Quant. Spec. Rad. Trans., 58, 85

Corliss, C. H., \& Bozman, W. R. 1962, Experimental Transition Probabilities for the Spectral Lines of Seventy Elements, U. S. Natl. Bur. Standards Monograph 53, (Washington: U. S. Government Printing Office)

Cowan, R. D. 1981, The Theory of Atomic Structure and Spectra, Univ. of California Press, Berkeley

Danzmann, K., \& Kock, M. 1982, J. Opt. Soc. Am., 721556

Delbouille, L., Roland, G., \& Neven, L. 1973, Photometric Atlas of the Solar Spectrum from $\lambda 3000$ to $\lambda 10000$ (Liége, Inst. D’Ap., Univ. de Liége)

Fitzpatrick, M. J. \& Sneden, C. 1987, BAAS, 19, 1129

Gratton, R. G., \& Sneden, C. 1991, A\&A, 241, 501

Grevesse, N., Noels, A, \& Sauval, A. J. 1996, ASPC, 99, 117

Grevesse, N., \& Sauval, A. J. 1998, Space Sci. Rev., 85, 161

Grevesse, N., \& Sauval, A. J. 1999, A\&A, 347, 348

Grigoriev, I. S., \& Melikhov, E. Z. 1997, Handbook of Physical Quantities (Boca Raton, CRC Press)

Gustaffson, B., Bell, R. A., Eriksson, K. \& Nordlund, A. 1975, A\&A, 42, 407

Gustafsson B., Edvardsson B., Eriksson K., Mizuno-Wiedner M., Jorgensen U. G., \& Plez B. 2003, ASP Conf. Ser. (I.Hubeny, D.Mihalas, K.Werner eds.), 288, 331

Halenka, J. \& Grabowski, B. 1986, A\&AS, 64, 496

Hannaford, P., \& Lowe, R. M. 1981, J. Phys. B, 14, L5

Hashiguchi, S., \& Hasikuni, M. 1985, J. Phys. Soc. Japan, 54, 1290

Heilig, K., \& Wendlandt D. 1967, Phys. Lett. A, 25, 277 
Holweger, H., \& Müller, E. A. 1974, Sol. Phys., 39, 19

Holweger, H., Kock, M., \& Bard, A. 1995, A\&A, 296, 233

Irwin, A. W. 1981, ApJS, 45, 621

King, J. R., Stephens, A., Boesgaard, A. M., \& Deliannis, C. P. 1998, AJ, 115, 666

Kupka F., Piskunov N.E., Ryabchikova T.A., Stempels H.C., \& Weiss W.W. 1999, A\&AS, 138,119

Kurucz, R. L., \& Peytremann, E. 1975, SAO Special Report No. 362, Part 1

Kurucz, R. L. 1993, Kurucz CD-ROM 13, ATLAS 9 (Cambridge:SAO)

Kwiatowski, M., Micali, G., Werner, K., \& Zimmerman, P. 1981, A\&A, 103, 108

Kwong, H. S., \& Measures, R. M. 1980, Appl. Opt., 19, 1025

Lodders, K. 2003, ApJ, 591, 1220

Luck, R. E., \& Heiter, U. 2005, AJ, 129, 1063

Magain, P. 1989, A\&A, 209, 211

Marek, J., \& Richter, J. 1973, A\&A, 26, 155

Marek, J. 1975, A\&A, 44, 69

Martin, G. A., Fuhr, J. R., \& Wiese, W. L. 1988, J. Phys. Chem. Ref. Data 17, Suppl. 3

McWilliam, A, Preston, G. W., Sneden, C., \& Searle, L. 1995, AJ, 109, 2757

Measures, R. M., Drewell, N., \& Kwong, H. S. 1977, Phys. Rev. A., 16, 1093

Milford, P. N., O’Mara, B. J., \& Ross, J. E. 1994, A\&A, 292, 276

Moore, C. E., Minnaert, M. G. J., \& Houtgast, J. 1966, The Solar Spectrum $2935 \AA$ to 8770 Å NBS Monograph 61 (Washington: U. S. G. P. O.)

Nakamura, T., Umeda, H., Nomoto,K., Thielmann, F. K., \& Burrow, A. 1999, ApJ, 517, 193

Nilsson, H., Ljung, G., Lundberg, H., \& Nielsen, K. E. 2006, A\&A, 445, 1165 
O’Mara, B. J., \& Barklem, P. S. 2003, Proc. 12th Cambridge Workshop on Cooler Stars, Stellar Systems, \& The Sun, 1097 (Colorado)

Ryan, S. G., Norris, J. E., \& Bessell, M. S. 1991, AJ, 102, 303

Schnabel, R., Kock, M. \& Holweger, H. 1999, A\&A, 342, 610

Shchukina, N. \& Trujillo Bueno, J. 2001, ApJ, 550, 970

Simmons, G. J., \& Blackwell, D. E. 1982, A\&A, 112, 209

Sneden, C. 1973, ApJ, 184, 839

Sneden, C., Preston, G. W., McWilliam, A., \& Searle, L. 1994, ApJ, 431, L27

Sneden, C., Cowan, J. J., Lawler, J. E., Ivans, I. I., Burles, S., Beers, T. C., Primas, F., Hill, V., Truran, J. W., Fuller, G. M., Pfeiffer, B., \& Kratz, K. L. 2003, ApJ, 591, 936

Sugar, J., \& Corliss, C. 1985, J. Phys. Chem. Ref. Data 14 Suppl., 2, 264

Takeda, Y., Hashimoto, O., Taguchi, H., Yoshioka, K., Takada-Hidai, M., Saito, Y., \& Honda, S. 2005, PASJ, 57, 751

Tozzi, G. P., Brunner, A. J., \& Huber, M. C. E. 1985, MNRAS, 217, 423

Unsöld, A. L. 1927, Z. Phys., 43, 563

Unsöld, A. L. 1955, Physik der Sternatmospharen, (Berlin: Springer-Verlag)

Valenti, J. A. \& Fischer D. A. 2005, ApJS, 159, 141

Whaling, W., Carle, M. T., \& Pitt, M. L. 1993, J. Quant. Spec. Rad. Trans., 50, 7

Wickliffe, M. E., Lawler, J. E., \& Nave, G. 2000, J. Quant. Spec. Rad. Trans., 66, 363

Wolnik, S. J., Berthel, R. O., Larson, G. S., Carnevale, E. H., \& Wares, G. W. 1968, Phys. Fluids, 11, 1002

Wolnik, S. J., Berthel, R. O., Carnevale, E. H., \& Wares, G. W. 1969, ApJ, 157, 983

Wujec, T., \& Weniger, S. 1981, J. Quant. Spec. Rad. Trans., 25, 167 

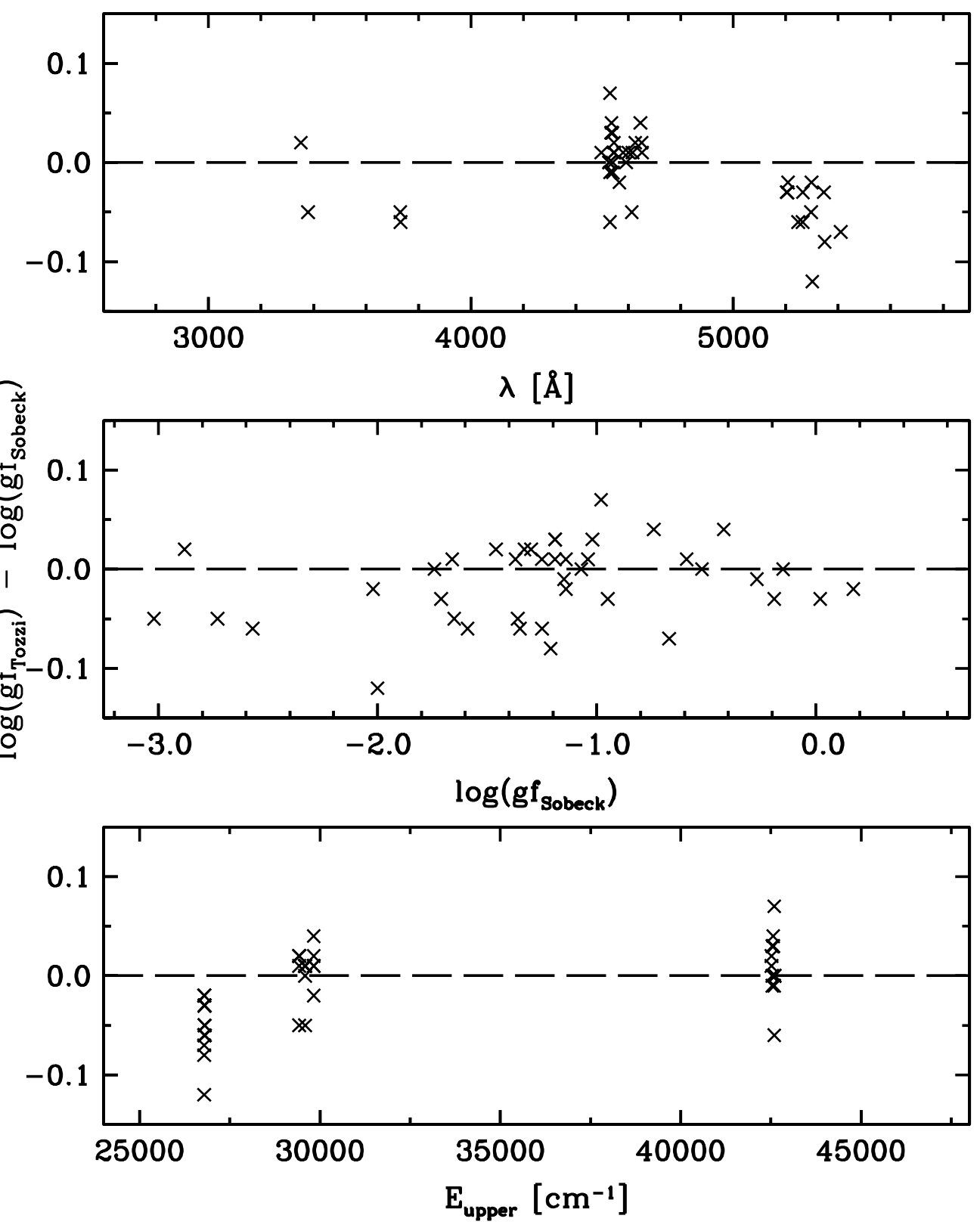

Fig. 1.- Comparison of our oscillator strength values to those of Tozzi et al. (1985). The upper panel shows the difference between the $\log \left(g f_{\text {Tozzi }}\right)$ and $\log \left(g f_{\text {Sobeck }}\right)$ as a function of wavelength. The middle panel displays the difference verus the $\log \left(g f_{\text {Sobeck }}\right)$ values. The bottom panel illustrates the difference as a function of upper energy level $\left(\mathrm{E}_{\text {upper }}\right)$. 


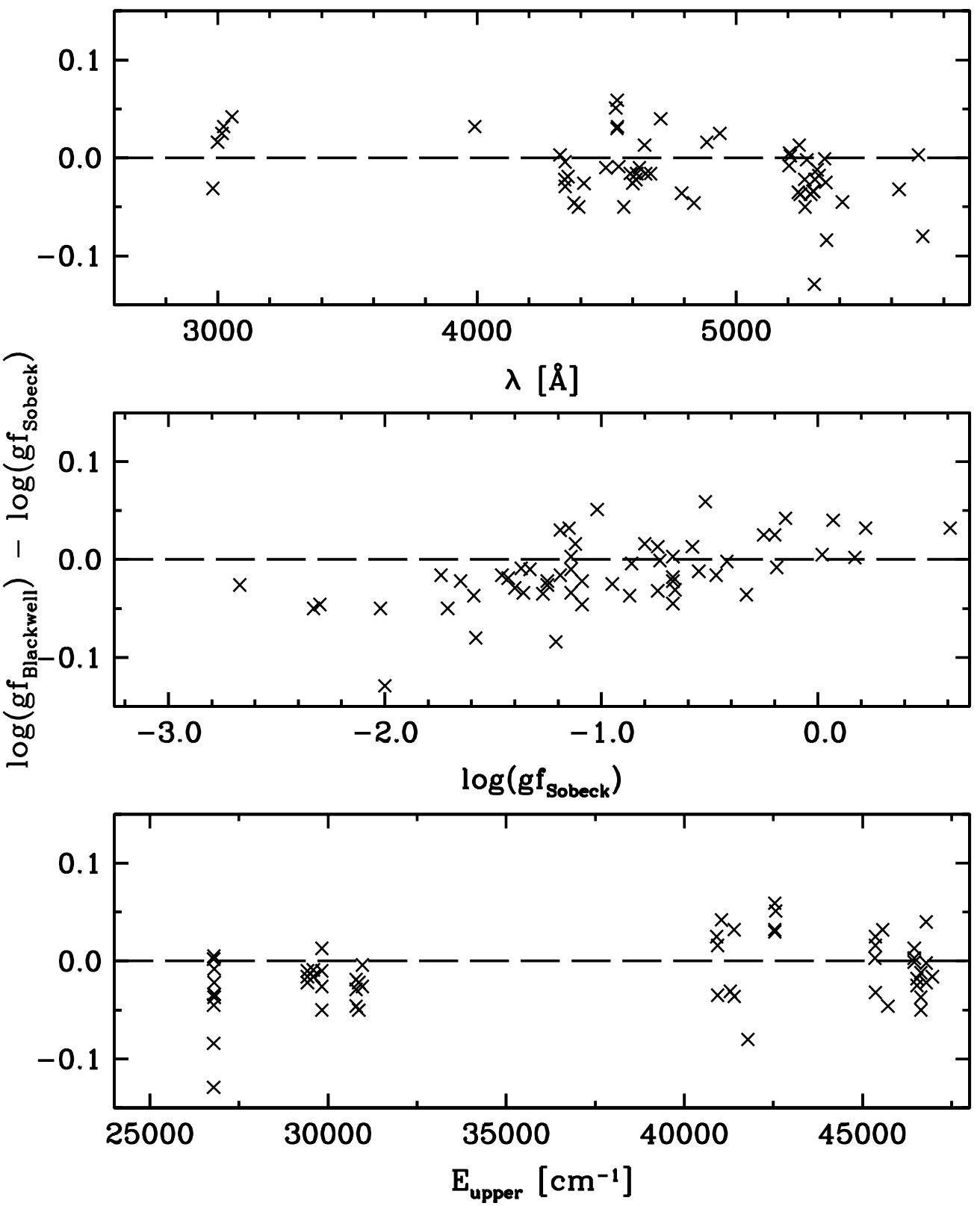

Fig. 2.- Comparison of our oscillator strength values to those of Blackwell et al. (1984, 1986). The upper panel shows the difference between the $\log \left(g f_{\text {Blackwell }}\right)$ and $\log \left(g f_{\text {Sobeck }}\right)$ as a function of wavelength. The middle panel displays the difference verus the $\log \left(g f_{\text {Sobeck }}\right)$ values. The bottom panel illustrates the difference as a function of upper energy level $\left(\mathrm{E}_{\text {upper }}\right)$. 

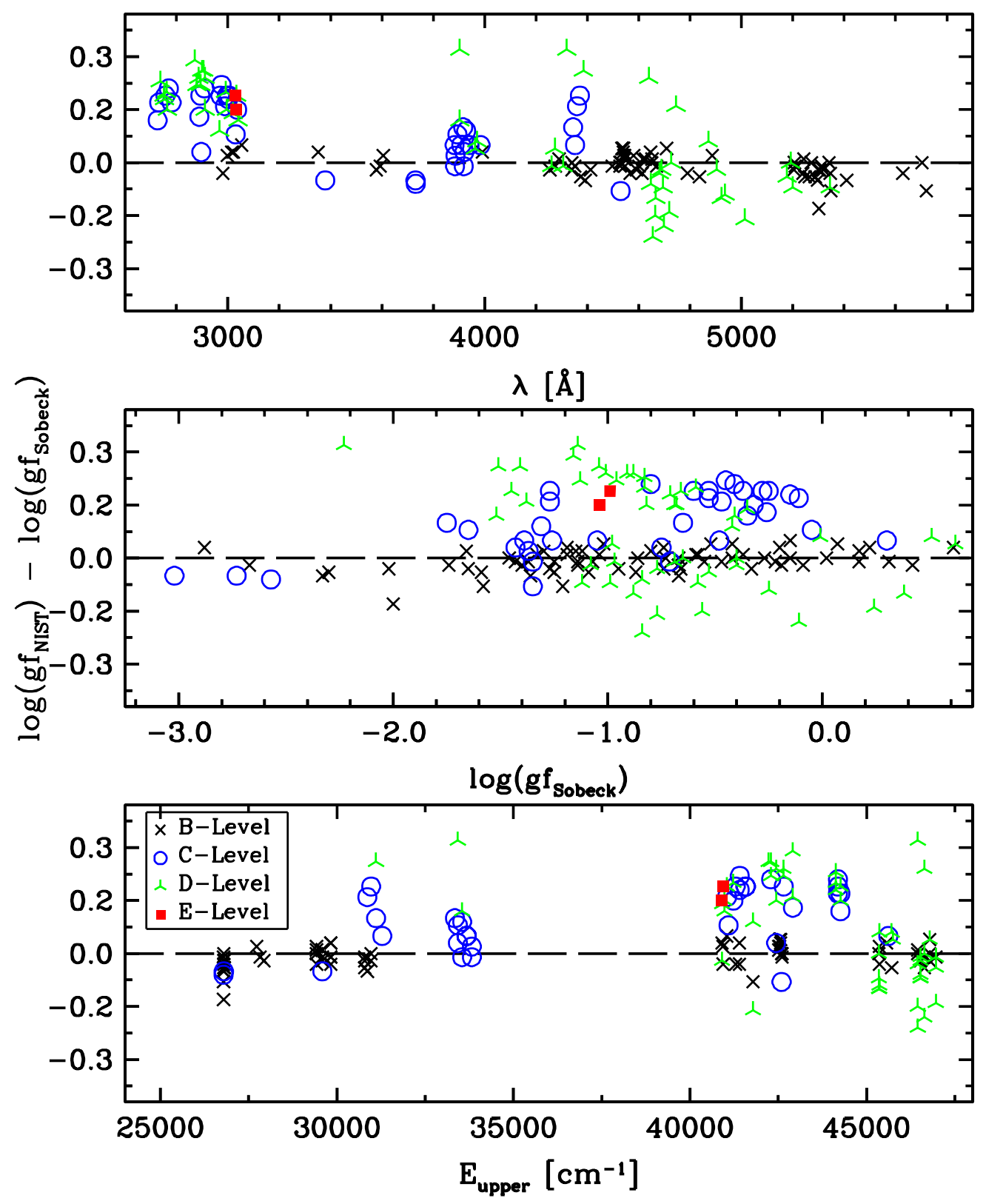

Fig. 3.- Comparison of our oscillator strength values to those of the NIST compilation. The upper panel shows the difference between the $\log \left(g f_{N I S T}\right)$ and $\log \left(g f_{\text {Sobeck }}\right)$ as a function of wavelength. The middle panel displays the difference verus the $\log \left(g f_{\text {Sobeck }}\right)$ values. The bottom panel illustrates the difference as a function of upper energy level $\left(\mathrm{E}_{\text {upper }}\right)$. 


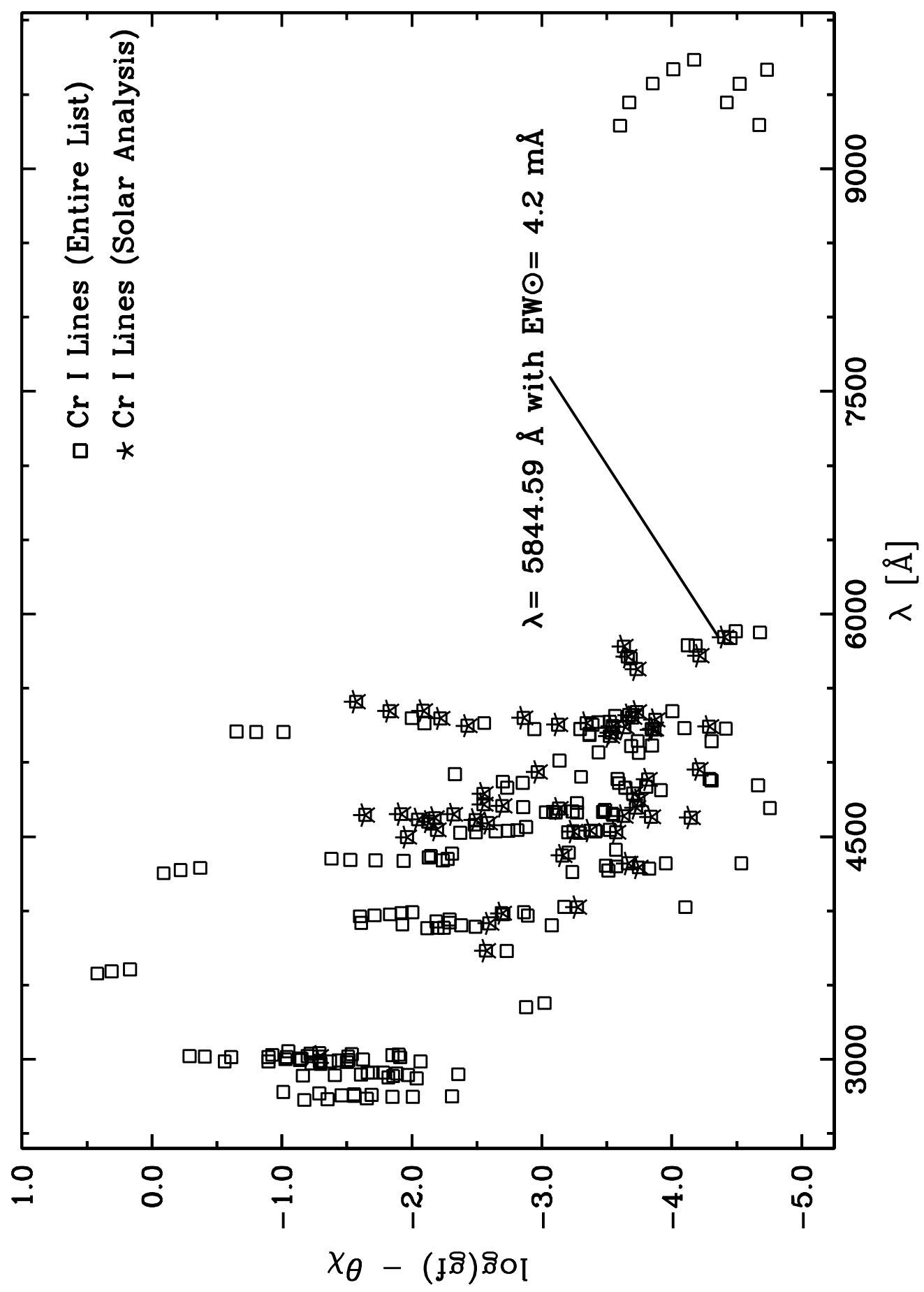

Fig. 4.- Relative strength factors (RSF) as defined by $\log (g f)-\theta \chi$ for the Cr I transitions. Reduced widths of weak lines should be proportional to these factors. For these computations, $\theta=0.87$, the inverse of the effective temperature of the Sun. The squares indicate the RSF for all $263 \mathrm{Cr}$ I lines and the stars designate those Cr I lines actually used in the derivation of the solar abundance. The $5844.59 \AA$ line is specially noted in the plot as it is has a small RSF yet is still detectable in the solar spectrum. 

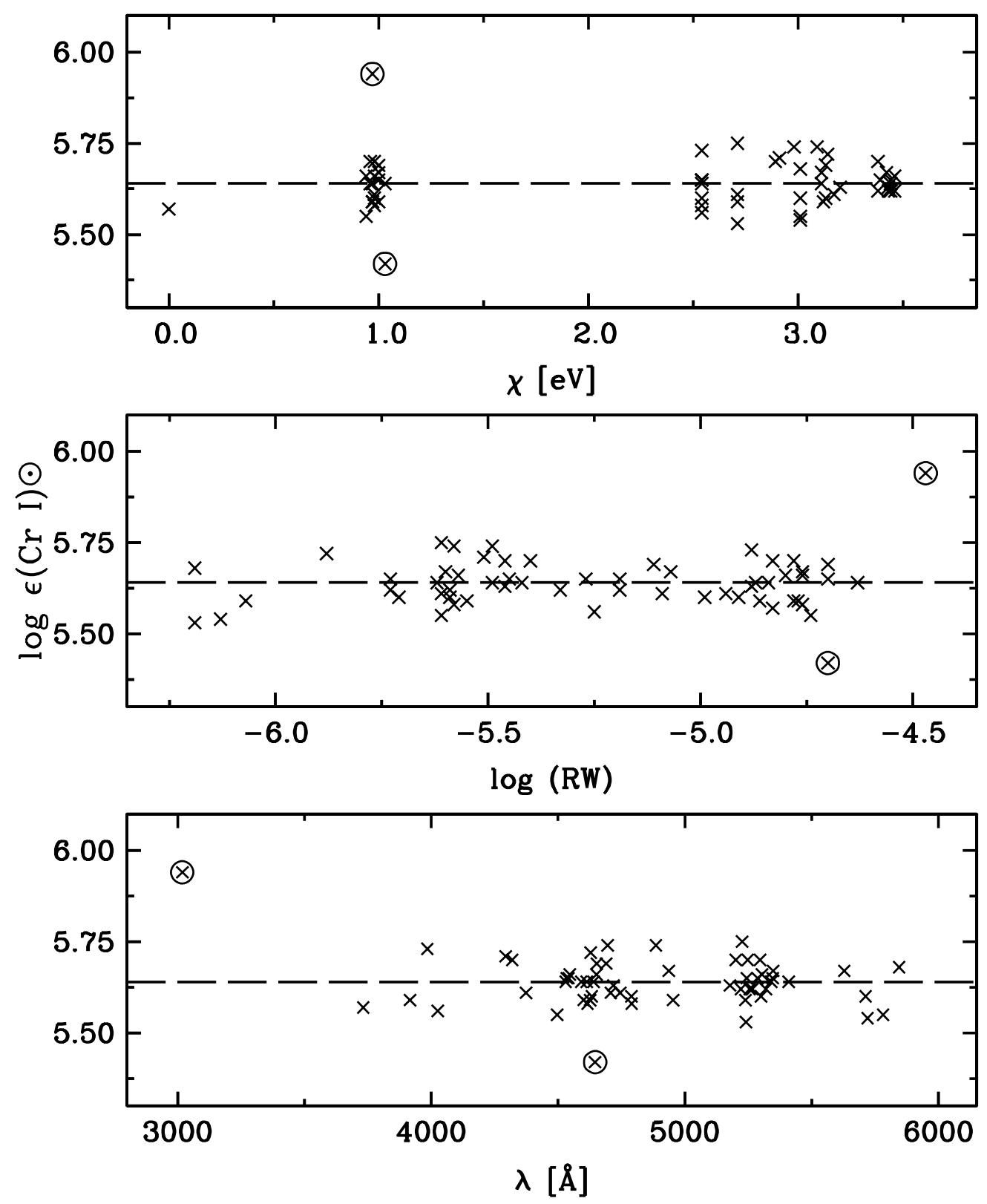

Fig. 5.- Plot of solar Cr I abundances as a function of excitation potential $(\chi)$, reduced width $(\log (\mathrm{RW}))$, and wavelength $(\lambda)$. Encircled in each of the three panels are the two most erroneous abundance values. Note that these two abundance data points correspond to lines that originate from major branches. Consequently, the error in these two points cannot be attributed to oscillator strength uncertainties. 

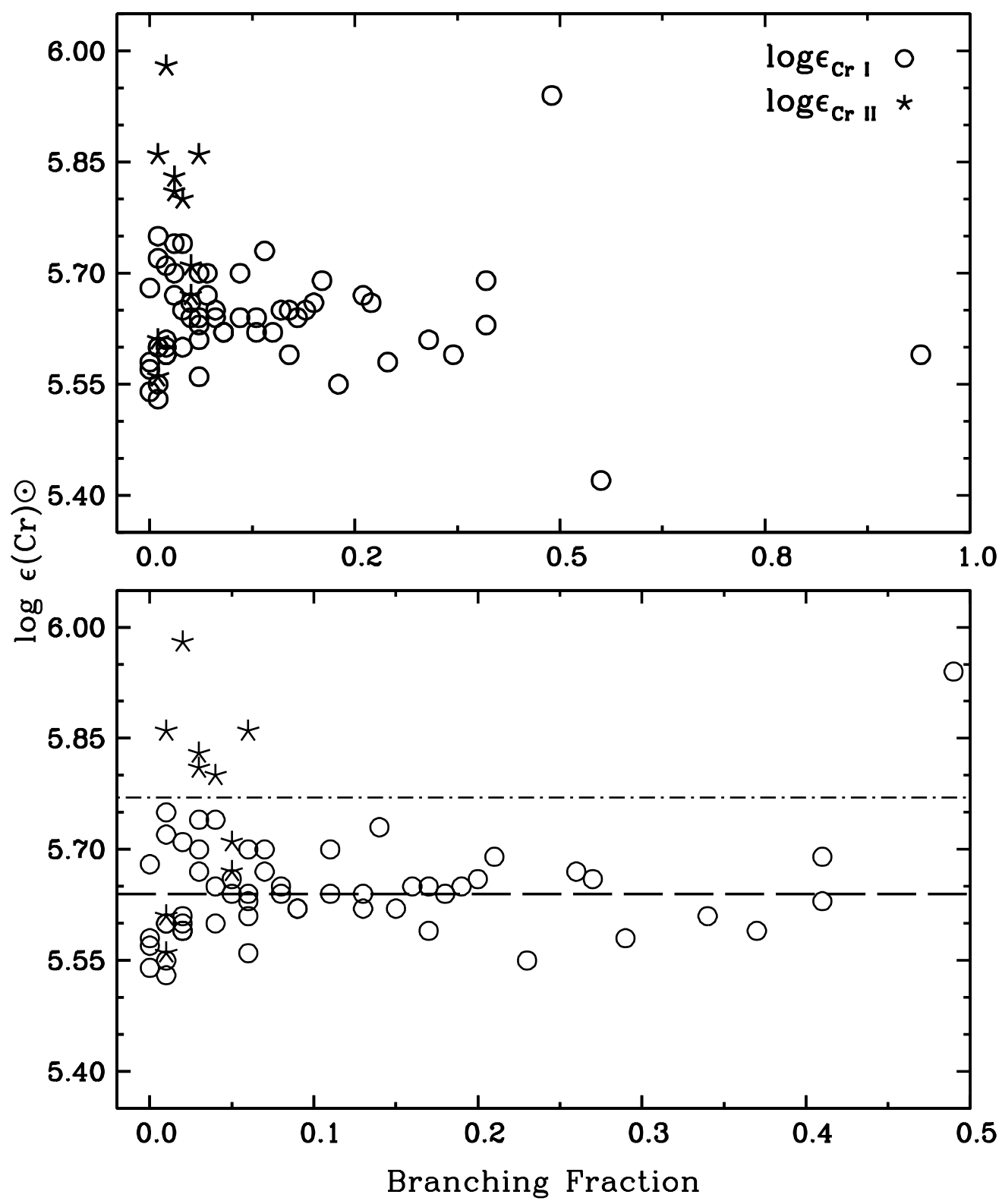

Fig. 6.- Branching Fractions for the Cr I and Cr II lines used in the solar abundance analysis. The lower panel (which is an enlarged view of the upper) shows the average abundance from the Cr I transitions (dashed line) as well as that from the Cr II transitions (dash-dotted line). 
Table 1. Radiative Lifetimes of 65 Cr I Levels from LIF Measurements

\begin{tabular}{|c|c|c|c|c|c|c|}
\hline Configuration & Term & $\mathrm{J}$ & $\begin{array}{l}\text { Level } \\
{\left[\mathrm{cm}^{-1}\right]}\end{array}$ & $\begin{array}{c}\tau[\mathrm{ns}] \\
\text { Cooper et al. } 1997\end{array}$ & $\begin{array}{l}\tau[\mathrm{ns}] \\
\text { Other LIF }\end{array}$ & $\begin{array}{c}\tau[\mathrm{ns}] \\
\text { Martin et al. } 1988\end{array}$ \\
\hline \multirow[t]{5}{*}{$3 \mathrm{~d}^{5}\left({ }^{6} \mathrm{~S}\right) 4 \mathrm{p}$} & $\mathrm{z}^{7} \mathrm{P}^{o}$ & 2 & 23305.01 & $32.2 \pm 1.6$ & $\begin{aligned} 31.42 & \pm 0.25^{a} \\
31.2 & \pm 1.0^{b}\end{aligned}$ & $\begin{array}{c}31.6 \\
\ldots\end{array}$ \\
\hline & & 3 & 23386.35 & $31.5 \pm 1.6$ & $32.22 \pm 0.17^{a}$ & 32.5 \\
\hline & & 4 & 23498.84 & $30.3 \pm 1.5$ & $31.15 \pm 0.08^{a}$ & 31.7 \\
\hline & & & & & $31.8 \pm 2.5^{c}$ & $\ldots$ \\
\hline & & & & & $31.6 \pm 0.5^{e}$ & $\ldots$ \\
\hline \multirow[t]{3}{*}{$3 \mathrm{~d}^{5}\left({ }^{6} \mathrm{~S}\right) 4 \mathrm{p}$} & $\mathrm{z}^{5} \mathrm{P}^{o}$ & 3 & 26787.50 & $16.2 \pm 0.8$ & $17.5 \pm 0.9^{d}$ & 17.0 \\
\hline & & 2 & 26796.28 & $16.2 \pm 0.8$ & $16.7 \pm 0.8^{d}$ & 16.5 \\
\hline & & 1 & 26801.93 & $16.0 \pm 0.8$ & $17.3 \pm 0.9^{d}$ & 16.7 \\
\hline \multirow[t]{3}{*}{$3 \mathrm{~d}^{4}\left({ }^{5} \mathrm{D}\right) 4 \mathrm{~s} 4 \mathrm{p}\left({ }^{3} \mathrm{P}^{o}\right)$} & $\mathrm{y}^{7} \mathrm{P}^{o}$ & 2 & 27728.87 & $6.6 \pm 0.3$ & $\ldots$ & 6.2 \\
\hline & & 3 & 27820.23 & $6.6 \pm 0.3$ & $\ldots$ & 6.7 \\
\hline & & 4 & 27935.26 & $6.6 \pm 0.3$ & $\ldots$ & 6.8 \\
\hline \multirow[t]{3}{*}{$3 \mathrm{~d}^{4}\left({ }^{5} \mathrm{D}\right) 4 \mathrm{~s} 4 \mathrm{p}\left({ }^{3} \mathrm{P}^{o}\right)$} & $\mathrm{y}^{5} \mathrm{P}^{o}$ & 1 & 29420.90 & $76.6 \pm 3.8$ & $72.8 \pm 5.5^{d}$ & 75.8 \\
\hline & & 2 & 29584.62 & $72.9 \pm 3.6$ & $70.6 \pm 3.6^{d}$ & 72.5 \\
\hline & & 3 & 29824.75 & $69.1 \pm 3.5$ & $63.5 \pm 3.0^{d}$ & 66.5 \\
\hline \multirow[t]{5}{*}{$3 \mathrm{~d}^{4}\left({ }^{5} \mathrm{D}\right) 4 \mathrm{~s} 4 \mathrm{p}\left({ }^{3} \mathrm{P}^{o}\right)$} & $\mathrm{z}^{5} \mathrm{~F}^{o}$ & 1 & 30787.30 & $101 \pm 5$ & $\ldots$ & 110 \\
\hline & & 2 & 30858.82 & $99.1 \pm 5.0$ & $\ldots$ & 89.5 \\
\hline & & 3 & 30965.46 & $99.9 \pm 5.0$ & $\ldots$ & 89.9 \\
\hline & & 4 & 31106.37 & $94.5 \pm 4.7$ & $\ldots$ & 73.0 \\
\hline & & 5 & 31280.35 & $91.3 \pm 4.6$ & $\ldots$ & 83.3 \\
\hline \multirow[t]{5}{*}{$3 \mathrm{~d}^{4}\left({ }^{5} \mathrm{D}\right) 4 \mathrm{~s} 4 \mathrm{p}\left({ }^{3} \mathrm{P}^{o}\right)$} & $\mathrm{z}^{5} \mathrm{D}^{o}$ & 0 & 33338.20 & $122 \pm 6$ & $\ldots$ & 103 \\
\hline & & 1 & 33423.79 & $102 \pm 5$ & $\ldots$ & 87.0 \\
\hline & & 2 & 33542.11 & $88.7 \pm 4.4$ & $\ldots$ & 79.4 \\
\hline & & 3 & 33671.55 & $83.9 \pm 4.2$ & $\ldots$ & 77.5 \\
\hline & & 4 & 33816.06 & $83.7 \pm 4.2$ & $\ldots$ & 87.7 \\
\hline \multirow[t]{4}{*}{$3 \mathrm{~d}^{4}\left({ }^{5} \mathrm{D}\right) 4 \mathrm{~s} 4 \mathrm{p}\left({ }^{1} \mathrm{P}^{o}\right)$} & $\mathrm{y}^{5} \mathrm{~F}^{o}$ & 1 & 40906.46 & $3.4 \pm 0.2$ & $\ldots$ & 2.8 \\
\hline & & 2 & 40971.29 & $4.5 \pm 0.2$ & $\ldots$ & $<8.6$ \\
\hline & & 3 & 41086.26 & $3.4 \pm 0.2$ & $\ldots$ & $<9.1$ \\
\hline & & 4 & 41224.78 & $3.4 \pm 0.2$ & $\ldots$ & $<18.5$ \\
\hline
\end{tabular}


Table 1-Continued

\begin{tabular}{|c|c|c|c|c|c|c|}
\hline Configuration & Term & $\mathrm{J}$ & $\begin{array}{l}\text { Level } \\
{\left[\mathrm{cm}^{-1}\right]}\end{array}$ & $\begin{array}{c}\tau[\mathrm{ns}] \\
\text { Cooper et al. } 1997\end{array}$ & $\begin{array}{c}\tau[\mathrm{ns}] \\
\text { Other LIF }\end{array}$ & $\begin{array}{l}\quad \tau[\mathrm{ns}] \\
\text { Martin et al. } 1988\end{array}$ \\
\hline & & 5 & 41393.47 & $3.5 \pm 0.2$ & $\ldots$ & 3.3 \\
\hline \multirow[t]{2}{*}{$3 \mathrm{~d}^{4}\left({ }^{5} \mathrm{D}\right) 4 \mathrm{~s} 4 \mathrm{p}\left({ }^{1} \mathrm{P}^{o}\right)$} & $\mathrm{x}^{5} \mathrm{P}^{o}$ & 1 & 40930.31 & $5.6 \pm 0.3$ & $\ldots$ & $<12.0$ \\
\hline & & 3 & 41043.35 & $6.1 \pm 0.3$ & $\ldots$ & $<6.0$ \\
\hline \multirow[t]{5}{*}{$3 \mathrm{~d}^{4}\left({ }^{5} \mathrm{D}\right) 4 \mathrm{~s} 4 \mathrm{p}\left({ }^{1} \mathrm{P}^{o}\right)$} & $\mathrm{y}{ }^{5} \mathrm{D}^{o}$ & 0 & 41224.80 & $5.0 \pm 0.3$ & $\ldots$ & 3.3 \\
\hline & & 1 & 41289.17 & $4.8 \pm 0.2$ & $\cdots$ & $<4.0$ \\
\hline & & 2 & 41409.03 & $4.7 \pm 0.2$ & $\ldots$ & $<4.0$ \\
\hline & & 3 & 41575.10 & $4.6 \pm 0.2$ & $\ldots$ & $<6.1$ \\
\hline & & 4 & 41782.19 & $4.5 \pm 0.2$ & $\ldots$ & $<23.3$ \\
\hline \multirow[t]{5}{*}{$3 \mathrm{~d}^{4}\left(\mathrm{a}^{3} \mathrm{P}\right) 4 \mathrm{~s} 4 \mathrm{p}\left({ }^{3} \mathrm{P}^{o}\right)$} & $\mathrm{x}^{5} \mathrm{D}^{o}$ & 0 & 42218.37 & $13.4 \pm 0.7$ & $\ldots$ & 7.7 \\
\hline & & 1 & 42292.96 & $13.7 \pm 0.7$ & $\cdots$ & 8.6 \\
\hline & & 2 & 42438.82 & $14.5 \pm 0.7$ & $\ldots$ & 11.0 \\
\hline & & 3 & 42648.26 & $16.0 \pm 0.8$ & $\ldots$ & 10.0 \\
\hline & & 4 & 42908.57 & $17.6 \pm 0.9$ & $\ldots$ & 12.5 \\
\hline \multirow[t]{5}{*}{$3 d^{5}\left({ }^{4} G\right) 4 p$} & $\mathrm{z}^{5} \mathrm{G}^{o}$ & 2 & 42515.35 & $48.7 \pm 2.4$ & $48.5 \pm 2.5^{d}$ & 49.3 \\
\hline & & 3 & 42538.81 & $49.0 \pm 2.5$ & $46.0 \pm 2.5^{d}$ & 46.3 \\
\hline & & 4 & 42564.85 & $48.8 \pm 2.4$ & $46.9 \pm 2.5^{d}$ & 47.2 \\
\hline & & 5 & 42589.25 & $48.7 \pm 2.4$ & $48.2 \pm 2.5^{d}$ & 48.8 \\
\hline & & 6 & 42605.81 & $50.0 \pm 2.5$ & $50.2 \pm 2.5^{d}$ & 51.0 \\
\hline \multirow[t]{3}{*}{$3 d^{5}\left({ }^{6} \mathrm{~S}\right) 5 \mathrm{p}$} & $\mathrm{w}^{5} \mathrm{P}^{o}$ & 1 & 44125.90 & $5.5 \pm 0.3$ & $\ldots$ & $<4.3$ \\
\hline & & 2 & 44186.92 & $5.4 \pm 0.3$ & $\ldots$ & $<3.9$ \\
\hline & & 3 & 44259.36 & $5.2 \pm 0.3$ & $\ldots$ & 3.8 \\
\hline \multirow[t]{3}{*}{$3 \mathrm{~d}^{5}\left({ }^{4} \mathrm{G}\right) 4 \mathrm{p}$} & $\mathrm{z} 3 \mathrm{H}^{\circ}$ & 6 & 45348.73 & $15.6 \pm 0.8$ & $\ldots$ & 20 \\
\hline & & 5 & 45354.18 & $15.6 \pm 0.8$ & $\ldots$ & $<21.1$ \\
\hline & & 4 & 45358.63 & $15.5 \pm 0.8$ & $\ldots$ & $<16.7$ \\
\hline \multirow[t]{5}{*}{$3 d^{5}\left({ }^{4} G\right) 4 p$} & $\mathrm{y}{ }^{5} \mathrm{H}^{o}$ & 3 & 45566.02 & $8.8 \pm 0.4$ & $\ldots$ & $<9.3$ \\
\hline & & 4 & 45614.88 & $8.9 \pm 0.4$ & $\ldots$ & $<9.2$ \\
\hline & & 5 & 45663.28 & $8.9 \pm 0.4$ & $\ldots$ & $<357$ \\
\hline & & 6 & 45707.36 & $8.8 \pm 0.4$ & $\ldots$ & $<8.2$ \\
\hline & & 7 & 45741.49 & $8.5 \pm 0.4$ & $\ldots$ & 7.7 \\
\hline
\end{tabular}


Table 1 - Continued

\begin{tabular}{lcccccc}
\hline \hline Configuration & Term & $\mathrm{J}$ & $\begin{array}{c}\text { Level } \\
{\left[\mathrm{cm}^{-1}\right]}\end{array}$ & $\begin{array}{c}\tau[\mathrm{ns}] \\
\text { Cooper et al. 1997 }\end{array}$ & $\begin{array}{c}\tau[\mathrm{ns}] \\
\text { Other LIF }\end{array}$ & $\begin{array}{c}\tau[\mathrm{ns}] \\
\text { Martin et al. 1988 }\end{array}$ \\
& & & & & \\
\hline $3 \mathrm{~d}^{4} 4 \mathrm{~s} 5 \mathrm{~s}$ & $\mathrm{f}{ }^{7} \mathrm{D}$ & 1 & 46448.60 & $8.7 \pm 0.4$ & $9.2 \pm 0.7^{c}$ & $<12.0$ \\
& 2 & 46524.84 & $8.7 \pm 0.4$ & $9.5 \pm 0.8^{c}$ & $<15.8$ \\
& 3 & 46637.21 & $8.6 \pm 0.4$ & $9.2 \pm 0.7^{c}$ & $<15.4$ \\
& 4 & 46783.06 & $8.7 \pm 0.4$ & $9.7 \pm 0.8^{c}$ & $<14.8$ \\
$3 \mathrm{~d}^{4}\left({ }^{3} \mathrm{H}\right) 4 \mathrm{~s} 4 \mathrm{p}\left({ }^{3} \mathrm{P}^{o}\right)$ & $\mathrm{x}^{5} \mathrm{G}^{o}$ & 5 & 46958.98 & $8.7 \pm 0.4$ & $9.8 \pm 0.8^{c}$ & $<17.6$ \\
& & 47047.47 & $16.3 \pm 0.8$ & $15.0 \pm 1.5^{d}$ & 15.9 \\
& & 4 & 47125.70 & $16.9 \pm 0.8$ & $15.2 \pm 1.0^{d}$ & 16.4 \\
& 4 & 47189.87 & $16.0 \pm 0.8$ & $\ldots$ & $<476$. \\
& 6 & 47222.27 & $13.2 \pm 0.7$ & $13.9 \pm 0.7^{d}$ & 12.3 \\
& 5 & 47228.80 & $14.9 \pm 0.7$ & $14.8 \pm 0.7^{d}$ & $<455$. \\
\hline
\end{tabular}

${ }^{a}$ IF Literature References: (a) Measures et al. 1977. (b) Kwong \& Measures 1980. (c) Marek 1975. (d) Kwiatowski et al. 1981. (e) Hannaford \& Lowe 1981. 
Table 2. FTS Spectra Chosen for Branching Fraction Determination

\begin{tabular}{|c|c|c|c|c|c|c|c|c|c|c|c|}
\hline $\begin{array}{l}\text { Spectrum } \\
\text { Number }\end{array}$ & $\begin{array}{c}\text { Date } \\
\text { Recorded }\end{array}$ & $\begin{array}{c}\text { Serial } \\
\text { Number }\end{array}$ & $\begin{array}{c}\mathrm{HC} \\
\text { Discharge }\end{array}$ & $\begin{array}{c}\mathrm{I}_{\text {Discharge }} \\
\text { [Amps] }\end{array}$ & $\begin{array}{c}\mathrm{P}_{\text {Buffer }} \\
\text { [Torr] }\end{array}$ & $\begin{array}{l}\text { Number of } \\
\text { Co-adds }\end{array}$ & $\begin{array}{c}\text { Spectral Coverage } \\
{\left[\mathrm{cm}^{-1}\right]}\end{array}$ & $\begin{array}{c}\text { Limit of } \\
\text { Resolution }\left[\mathrm{cm}^{-1}\right]\end{array}$ & $\begin{array}{l}\text { Beam } \\
\text { Splitter }\end{array}$ & Filter(s) & $\begin{array}{l}\text { Photodiode } \\
\text { Detector }\end{array}$ \\
\hline 1 & 06-25-1982 & 7 & $\mathrm{Cr}-\mathrm{Ar}$ & 0.50 & 0.65 & 8 & 7664-44591 & 0.057 & UV & CS 9-54 & Mid Range Si \\
\hline 2 & $06-26-1982$ & 4 & $\mathrm{Cr}-\mathrm{Ar}$ & 0.10 & 1.00 & 6 & $7664-44591$ & 0.057 & UV & CS 9-54 & Mid Range Si \\
\hline 3 & 07-26-1984 & 6 & $\mathrm{Cr}-\mathrm{Ne}$ & 0.75 & 3.00 & 4 & $7985-45407$ & 0.054 & UV & WG295 & Mid Range Si \\
\hline 4 & $07-26-1984$ & 7 & $\mathrm{Cr}-\mathrm{Ne}$ & 1.50 & 3.30 & 4 & $7985-45407$ & 0.054 & UV & WG295 & Mid Range Si \\
\hline 5 & 07-26-1984 & 8 & $\mathrm{Cr}-\mathrm{Ne}$ & 1.50 & 3.30 & 4 & $7985-45407$ & 0.054 & UV & WG295 & Mid Range Si \\
\hline 6 & $02-28-1980$ & 1 & $\mathrm{Cr}-\mathrm{Ar}$ & 0.50 & 2.50 & 4 & $7908-28921$ & 0.035 & Vis & GG375 & Super Blue Si \\
\hline 7 & $03-25-1980$ & 3 & $\mathrm{Cr}-\mathrm{Ne}$ & 0.95 & 4.00 & 10 & $13489-27089$ & 0.034 & Vis & GG400/CS 4.96 & Super Blue Si \\
\hline
\end{tabular}


Table 3. Atomic Transition Probabilities for Cr I Organized by Increasing Wavelength in $\lambda_{\text {air }}$

\begin{tabular}{|c|c|c|c|c|c|c|c|c|c|}
\hline $\begin{array}{l}\lambda_{a i r} \\
{[\AA]}\end{array}$ & $\begin{array}{c}\mathrm{E}_{\text {upper }} \\
{\left[\mathrm{cm}^{-1}\right]}\end{array}$ & Term & $\mathrm{J}_{\text {upper }}$ & $\begin{array}{c}\mathrm{E}_{\text {lower }} \\
{\left[\mathrm{cm}^{-1}\right]}\end{array}$ & Term & $\mathrm{J}_{\text {lower }}$ & $\begin{array}{c}\mathrm{A}_{L S c a l c} \\
{\left[10^{6} \mathrm{~s}^{-1}\right]}\end{array}$ & $\begin{array}{c}\mathrm{A}_{\operatorname{Exp}} \\
{\left[10^{6} \mathrm{~s}^{-1}\right]}\end{array}$ & $\log g f$ \\
\hline 2726.50 & 44259.36 & $\mathrm{w}^{5} \mathrm{P}^{o}$ & 3 & 7593.16 & $a^{5} S$ & 2 & $\ldots$ & $58 \pm 3$ & -0.35 \\
\hline 2731.90 & 44186.92 & $\mathrm{w}^{5} \mathrm{P}^{o}$ & 2 & 7593.16 & $a^{5} \mathrm{~S}$ & 2 & $\ldots$ & $52 \pm 3$ & -0.53 \\
\hline 2736.46 & 44125.90 & $\mathrm{w}^{5} \mathrm{P}^{o}$ & 1 & 7593.16 & $a^{5} \mathrm{~S}$ & 2 & $\ldots$ & $43 \pm 4$ & -0.83 \\
\hline 2748.24 & 44186.92 & $\mathrm{w}^{5} \mathrm{P}^{o}$ & 2 & 7810.82 & $a^{5} D$ & 1 & $\ldots$ & $12.3 \pm 2.0$ & -1.16 \\
\hline 2748.32 & 44125.90 & $\mathrm{w}^{5} \mathrm{P}^{o}$ & 1 & 7750.78 & $a^{5} D$ & 0 & $\ldots$ & $29 \pm 3$ & -1.01 \\
\hline 2751.59 & 44259.36 & $\mathrm{w}^{5} \mathrm{P}^{o}$ & 3 & 7927.47 & $a^{5} D$ & 2 & $\ldots$ & $4.42 \pm 0.26$ & -1.45 \\
\hline 2752.86 & 44125.90 & $\mathrm{w}^{5} \mathrm{P}^{o}$ & 1 & 7810.82 & $a^{5} \mathrm{D}$ & 1 & $\ldots$ & $57 \pm 4$ & -0.71 \\
\hline 2757.09 & 44186.92 & $\mathrm{w}^{5} \mathrm{P}^{o}$ & 2 & 7927.47 & $a^{5} D$ & 2 & $\ldots$ & $44 \pm 3$ & -0.60 \\
\hline 2761.73 & 44125.90 & $\mathrm{w}^{5} \mathrm{P}^{o}$ & 1 & 7927.47 & $a^{5} D$ & 2 & $\ldots$ & $43 \pm 4$ & -0.83 \\
\hline 2764.35 & 44259.36 & $\mathrm{w}^{5} \mathrm{P}^{o}$ & 3 & 8095.21 & $a^{5} D$ & 3 & $\ldots$ & $25.9 \pm 2.1$ & -0.68 \\
\hline 2769.90 & 44186.92 & $\mathrm{w}^{5} \mathrm{P}^{o}$ & 2 & 8095.21 & $a^{5} D$ & 3 & $\ldots$ & $68 \pm 4$ & -0.41 \\
\hline 2780.68 & 44259.36 & $\mathrm{w}^{5} \mathrm{P}^{o}$ & 3 & 8307.57 & $a^{5} \mathrm{D}$ & 4 & $\ldots$ & $95 \pm 5$ & -0.11 \\
\hline 2871.62 & 42908.57 & $\mathrm{x}^{5} \mathrm{D}^{o}$ & 4 & 8095.21 & $a^{5} \mathrm{D}$ & 3 & $\ldots$ & $6.2 \pm 0.4$ & -1.16 \\
\hline 2879.27 & 42648.26 & $\mathrm{x}^{5} \mathrm{D}^{o}$ & 3 & 7927.47 & $a^{5} D$ & 2 & $\cdots$ & $12.6 \pm 0.7$ & -0.96 \\
\hline 2886.99 & 42438.82 & $\mathrm{x}^{5} \mathrm{D}^{o}$ & 2 & 7810.82 & $a^{5} D$ & 1 & $\ldots$ & $18.0 \pm 1.3$ & -0.95 \\
\hline 2889.24 & 42908.57 & $\mathrm{x}^{5} \mathrm{D}^{o}$ & 4 & 8307.57 & $a^{5} D$ & 4 & $\ldots$ & $49.1 \pm 2.5$ & -0.26 \\
\hline 2893.25 & 42648.26 & $\mathrm{x}^{5} \mathrm{D}^{o}$ & 3 & 8095.21 & $a^{5} D$ & 3 & $\ldots$ & $33.6 \pm 1.8$ & -0.53 \\
\hline 2894.16 & 42292.96 & $\mathrm{x}^{5} \mathrm{D}^{o}$ & 1 & 7750.78 & $a^{5} D$ & 0 & $\ldots$ & $19.6 \pm 1.4$ & -1.13 \\
\hline 2896.75 & 42438.82 & $\mathrm{x}^{5} \mathrm{D}^{o}$ & 2 & 7927.47 & $a^{5} D$ & 2 & $\ldots$ & $22.2 \pm 1.3$ & -0.85 \\
\hline 2899.20 & 42292.96 & $\mathrm{x}^{5} \mathrm{D}^{o}$ & 1 & 7810.82 & $a^{5} \mathrm{D}$ & 1 & $\ldots$ & $8.2 \pm 1.1$ & -1.51 \\
\hline 2905.49 & 42218.37 & $\mathrm{x}^{5} \mathrm{D}^{o}$ & 0 & 7810.82 & $a^{5} D$ & 1 & $\cdots$ & $72 \pm 5$ & -1.04 \\
\hline 2909.04 & 42292.96 & $\mathrm{x}^{5} \mathrm{D}^{o}$ & 1 & 7927.47 & $a^{5} D$ & 2 & $\cdots$ & $41.8 \pm 2.4$ & -0.80 \\
\hline 2910.90 & 42438.82 & $\mathrm{x}^{5} \mathrm{D}^{o}$ & 2 & 8095.21 & $a^{5} D$ & 3 & $\cdots$ & $27.5 \pm 1.6$ & -0.76 \\
\hline 2911.14 & 42648.26 & $\mathrm{x}^{5} \mathrm{D}^{o}$ & 3 & 8307.57 & $a^{5} D$ & 4 & $\ldots$ & $14.7 \pm 0.9$ & -0.88 \\
\hline 2967.64 & 41782.19 & $\mathrm{y}^{5} \mathrm{D}^{o}$ & 4 & 8095.21 & $a^{5} D$ & 3 & $\ldots$ & $31.8 \pm 1.8$ & -0.42 \\
\hline 2971.11 & 41575.10 & $\mathrm{y}^{5} \mathrm{D}^{o}$ & 3 & 7927.47 & $a^{5} D$ & 2 & $\ldots$ & $45.9 \pm 2.4$ & -0.37 \\
\hline 2975.48 & 41409.03 & $\mathrm{y}^{5} \mathrm{D}^{o}$ & 2 & 7810.82 & $a^{5} D$ & 1 & $\ldots$ & $53.8 \pm 2.9$ & -0.45 \\
\hline 2980.79 & 41289.17 & $\mathrm{y}^{5} \mathrm{D}^{o}$ & 1 & 7750.78 & $a^{5} D$ & 0 & $\ldots$ & $55 \pm 3$ & -0.66 \\
\hline 2985.85 & 41409.03 & $\mathrm{y}^{5} \mathrm{D}^{o}$ & 2 & 7927.47 & $a^{5} D$ & 2 & $\ldots$ & $45.9 \pm 2.6$ & -0.51 \\
\hline
\end{tabular}


Table 3-Continued

\begin{tabular}{|c|c|c|c|c|c|c|c|c|c|}
\hline $\begin{array}{l}\lambda_{\text {air }} \\
{[\AA]}\end{array}$ & $\begin{array}{l}\mathrm{E}_{\text {upper }} \\
{\left[\mathrm{cm}^{-1}\right]}\end{array}$ & Term & $\mathrm{J}_{\text {upper }}$ & $\begin{array}{l}\mathrm{E}_{\text {lower }} \\
{\left[\mathrm{cm}^{-1}\right]}\end{array}$ & Term & $\mathrm{J}_{\text {lower }}$ & $\begin{array}{c}\mathrm{A}_{L S \text { salc }} \\
{\left[10^{6} \mathrm{~S}^{-1}\right]}\end{array}$ & $\begin{array}{c}\mathrm{A}_{\operatorname{Exp}} \\
{\left[10^{6} \mathrm{~s}^{-1}\right]}\end{array}$ & $\log g f$ \\
\hline 2986.00 & 41575.10 & $\mathrm{y}^{5} \mathrm{D}^{o}$ & 3 & 8095.21 & $a^{5} D$ & 3 & $\ldots$ & $102 \pm 5$ & -0.02 \\
\hline 2986.13 & 41289.17 & $\mathrm{y}^{5} \mathrm{D}^{o}$ & 1 & 7810.82 & $a^{5} D$ & 1 & $\ldots$ & $14.9 \pm 2.1$ & -1.22 \\
\hline 2986.47 & 41782.19 & $\mathrm{y}^{5} \mathrm{D}^{o}$ & 4 & 8307.57 & $a^{5} D$ & 4 & $\ldots$ & $183 \pm 9$ & 0.34 \\
\hline 2988.65 & 41043.35 & $\mathrm{x}^{5} \mathrm{P}^{o}$ & 3 & 7593.16 & $a^{5} \mathrm{~S}$ & 2 & $\ldots$ & $35.9 \pm 2.0$ & -0.47 \\
\hline 2991.89 & 41224.80 & $\mathrm{y}^{5} \mathrm{D}^{o}$ & 0 & 7810.82 & $a^{5} \mathrm{D}$ & 1 & $\ldots$ & $192 \pm 10$ & -0.59 \\
\hline 2995.10 & 40971.29 & $\mathrm{y}^{5} \mathrm{~F}^{o}$ & 2 & 7593.16 & $a^{5} \mathrm{~S}$ & 2 & $\ldots$ & $30.6 \pm 2.1$ & -0.69 \\
\hline 2996.58 & 41289.17 & $\mathrm{y}^{5} \mathrm{D}^{o}$ & 1 & 7927.47 & $a^{5} \mathrm{D}$ & 2 & $\ldots$ & $130 \pm 7$ & -0.28 \\
\hline 2998.78 & 40930.31 & $\mathrm{x}^{5} \mathrm{P}^{o}$ & 1 & 7593.16 & $a^{5} \mathrm{~S}$ & 2 & $\ldots$ & $39.3 \pm 2.3$ & -0.80 \\
\hline 3000.88 & 41409.03 & $\mathrm{y}^{5} \mathrm{D}^{o}$ & 2 & 8095.21 & $a^{5} D$ & 3 & $\ldots$ & $105 \pm 5$ & -0.15 \\
\hline 3005.06 & 41575.10 & $\mathrm{y}^{5} \mathrm{D}^{o}$ & 3 & 8307.57 & $a^{5} D$ & 4 & $\ldots$ & $60 \pm 3$ & -0.25 \\
\hline 3013.03 & 40930.31 & $\mathrm{x}^{5} \mathrm{P}^{o}$ & 1 & 7750.78 & $a^{5} \mathrm{D}$ & 0 & $\ldots$ & $20.8 \pm 1.4$ & -1.07 \\
\hline 3014.76 & 40971.29 & $\mathrm{y}^{5} \mathrm{~F}^{o}$ & 2 & 7810.82 & $a^{5} D$ & 1 & $\ldots$ & $130 \pm 7$ & -0.05 \\
\hline 3014.91 & 41086.26 & $\mathrm{y}^{5} \mathrm{~F}^{o}$ & 3 & 7927.47 & $a^{5} D$ & 2 & $\ldots$ & $188 \pm 11$ & 0.25 \\
\hline 3015.20 & 40906.46 & $\mathrm{y}^{5} \mathrm{~F}^{o}$ & 1 & 7750.78 & $a^{5} D$ & 0 & $\ldots$ & $155 \pm 9$ & -0.20 \\
\hline 3017.57 & 41224.78 & $\mathrm{y}^{5} \mathrm{~F}^{o}$ & 4 & 8095.21 & $a^{5} \mathrm{D}$ & 3 & $\ldots$ & $242 \pm 14$ & 0.47 \\
\hline 3018.49 & 40930.31 & $\mathrm{x}^{5} \mathrm{P}^{o}$ & 1 & 7810.82 & $a^{5} D$ & 1 & $\ldots$ & $88 \pm 5$ & -0.44 \\
\hline 3018.82 & 41043.35 & $\mathrm{x}^{5} \mathrm{P}^{o}$ & 3 & 7927.47 & $a^{5} D$ & 2 & $\ldots$ & $23.3 \pm 1.6$ & -0.65 \\
\hline 3020.67 & 40906.46 & $\mathrm{y}^{5} \mathrm{~F}^{o}$ & 1 & 7810.82 & $a^{5} D$ & 1 & $\ldots$ & $110 \pm 7$ & -0.35 \\
\hline 3021.56 & 41393.47 & $\mathrm{y}^{5} \mathrm{~F}^{o}$ & 5 & 8307.57 & $a^{5} D$ & 4 & $\ldots$ & $272 \pm 16$ & 0.61 \\
\hline 3029.16 & 40930.31 & $\mathrm{x}^{5} \mathrm{P}^{o}$ & 1 & 7927.47 & $a^{5} \mathrm{D}$ & 2 & $\ldots$ & $25.0 \pm 1.4$ & -0.99 \\
\hline 3030.24 & 41086.26 & $\mathrm{y}^{5} \mathrm{~F}^{o}$ & 3 & 8095.21 & $a^{5} \mathrm{D}$ & 3 & $\ldots$ & $91 \pm 6$ & -0.06 \\
\hline 3031.35 & 40906.46 & $\mathrm{y}^{5} \mathrm{~F}^{o}$ & 1 & 7927.47 & $a^{5} D$ & 2 & $\ldots$ & $22.0 \pm 1.5$ & -1.04 \\
\hline 3034.19 & 41043.35 & $\mathrm{x}^{5} \mathrm{P}^{o}$ & 3 & 8095.21 & $a^{5} D$ & 3 & $\ldots$ & $22.7 \pm 1.3$ & -0.66 \\
\hline 3037.04 & 41224.78 & $\mathrm{y}^{5} \mathrm{~F}^{o}$ & 4 & 8307.57 & $a^{5} D$ & 4 & $\ldots$ & $38.5 \pm 2.4$ & -0.32 \\
\hline 3040.84 & 40971.29 & $\mathrm{y}^{5} \mathrm{~F}^{o}$ & 2 & 8095.21 & $a^{5} D$ & 3 & $\ldots$ & $56 \pm 3$ & -0.41 \\
\hline 3053.87 & 41043.35 & $\mathrm{x}^{5} \mathrm{P}^{o}$ & 3 & 8307.57 & $a^{5} D$ & 4 & $\ldots$ & $73 \pm 4$ & -0.15 \\
\hline 3351.96 & 29824.75 & $\mathrm{y}^{5} \mathrm{P}^{o}$ & 3 & 0.00 & $a^{7} S$ & 3 & $\ldots$ & $0.111 \pm 0.015$ & -2.88 \\
\hline 3379.16 & 29584.62 & $\mathrm{y}^{5} \mathrm{P}^{o}$ & 2 & 0.00 & $a^{7} \mathrm{~S}$ & 3 & $\ldots$ & $0.111 \pm 0.013$ & -3.02 \\
\hline 3578.68 & 27935.26 & $\mathrm{y}^{7} \mathrm{P}^{o}$ & 4 & 0.00 & $a^{7} S$ & 3 & $\ldots$ & $152 \pm 8$ & 0.42 \\
\hline
\end{tabular}


Table 3-Continued

\begin{tabular}{|c|c|c|c|c|c|c|c|c|c|}
\hline $\begin{array}{l}\lambda_{\text {air }} \\
{[\AA]}\end{array}$ & $\begin{array}{l}\mathrm{E}_{\text {upper }} \\
{\left[\mathrm{cm}^{-1}\right]}\end{array}$ & Term & $\mathrm{J}_{\text {upper }}$ & $\begin{array}{l}\mathrm{E}_{\text {lower }} \\
{\left[\mathrm{cm}^{-1}\right]}\end{array}$ & Term & $\mathrm{J}_{\text {lower }}$ & $\begin{array}{l}\mathrm{A}_{\text {LScalc }} \\
{\left[10^{6} \mathrm{~s}^{-1}\right]}\end{array}$ & $\begin{array}{c}\mathrm{A}_{\operatorname{Exp}} \\
{\left[10^{6} \mathrm{~S}^{-1}\right]}\end{array}$ & $\log g f$ \\
\hline 3593.48 & 27820.23 & $\mathrm{y}^{7} \mathrm{P}^{o}$ & 3 & 0.00 & $a^{7} S$ & 3 & $\ldots$ & $151 \pm 8$ & 0.31 \\
\hline 3605.32 & 27728.87 & $\mathrm{y}^{7} \mathrm{P}^{o}$ & 2 & 0.00 & $a^{7} S$ & 3 & $\ldots$ & $151 \pm 8$ & 0.17 \\
\hline 3730.80 & 26796.28 & $\mathrm{z}^{5} \mathrm{P}^{o}$ & 2 & 0.00 & $a^{7} S$ & 3 & $\ldots$ & $0.177 \pm 0.016$ & -2.73 \\
\hline 3732.02 & 26787.50 & $\mathrm{z}^{5} \mathrm{P}^{o}$ & 3 & 0.00 & $a^{7} S$ & 3 & $\ldots$ & $0.184 \pm 0.024$ & -2.57 \\
\hline 3742.96 & 47228.80 & $x^{5} G^{o}$ & 5 & 20519.60 & $a^{5} \mathrm{G}$ & 6 & $\ldots$ & $5.1 \pm 0.3$ & -0.93 \\
\hline 3743.54 & 47228.80 & $\mathrm{x}^{5} \mathrm{G}^{o}$ & 5 & 20523.69 & $a^{5} \mathrm{G}$ & 4 & $\ldots$ & $7.5 \pm 0.7$ & -0.76 \\
\hline 3743.57 & 47228.80 & $\mathrm{x}^{5} \mathrm{G}^{o}$ & 5 & 20523.94 & $a^{5} \mathrm{G}$ & 5 & $\ldots$ & $50.8 \pm 2.6$ & 0.07 \\
\hline 3743.88 & 47222.27 & $x^{5} G^{o}$ & 6 & 20519.60 & $a^{5} \mathrm{G}$ & 6 & $\ldots$ & $71 \pm 4$ & 0.29 \\
\hline 3744.49 & 47222.27 & $\mathrm{x}^{5} \mathrm{G}^{\circ}$ & 6 & 20523.94 & $a^{5} \mathrm{G}$ & 5 & $\ldots$ & $4.97 \pm 0.28$ & -0.87 \\
\hline 3748.61 & 47189.87 & $\mathrm{x}^{5} \mathrm{G}^{o}$ & 4 & 20520.92 & $a^{5} \mathrm{G}$ & 3 & $\ldots$ & $7.8 \pm 0.5$ & -0.83 \\
\hline 3749.00 & 47189.87 & $\mathrm{x}^{5} \mathrm{G}^{o}$ & 4 & 20523.69 & $a^{5} G$ & 4 & $\ldots$ & $41.7 \pm 2.2$ & -0.10 \\
\hline 3749.04 & 47189.87 & $\mathrm{x}^{5} \mathrm{G}^{\circ}$ & 4 & 20523.94 & $a^{5} \mathrm{G}$ & 5 & $\ldots$ & $8.8 \pm 0.8$ & -0.78 \\
\hline 3757.16 & 47125.70 & $x^{5} G^{o}$ & 3 & 20517.40 & $a^{5} G$ & 2 & $\ldots$ & $6.2 \pm 0.5$ & -1.04 \\
\hline 3757.66 & 47125.70 & $\mathrm{x}^{5} \mathrm{G}^{\circ}$ & 3 & 20520.92 & $a^{5} \mathrm{G}$ & 3 & $\ldots$ & $37.7 \pm 2.0$ & -0.25 \\
\hline 3758.05 & 47125.70 & $\mathrm{x}^{5} \mathrm{G}^{o}$ & 3 & 20523.69 & $a^{5} \mathrm{G}$ & 4 & $\ldots$ & $10.6 \pm 0.7$ & -0.81 \\
\hline 3768.24 & 47047.47 & $\mathrm{x}^{5} \mathrm{G}^{o}$ & 2 & 20517.40 & $a^{5} \mathrm{G}$ & 2 & $\ldots$ & $48.1 \pm 2.5$ & -0.29 \\
\hline 3768.74 & 47047.47 & $\mathrm{x}^{5} \mathrm{G}^{o}$ & 2 & 20520.92 & $a^{5} \mathrm{G}$ & 3 & $\ldots$ & $11.3 \pm 0.8$ & -0.92 \\
\hline 3883.29 & 33671.55 & $\mathrm{z}^{5} \mathrm{D}^{o}$ & 3 & 7927.47 & $a^{5} \mathrm{D}$ & 2 & $\ldots$ & $3.46 \pm 0.18$ & -1.26 \\
\hline 3885.22 & 33542.11 & $\mathrm{z}^{5} \mathrm{D}^{o}$ & 2 & 7810.82 & $a^{5} \mathrm{D}$ & 1 & $\ldots$ & $3.94 \pm 0.20$ & -1.35 \\
\hline 3886.80 & 33816.06 & $\mathrm{z}^{5} \mathrm{D}^{o}$ & 4 & 8095.21 & $a^{5} \mathrm{D}$ & 3 & $\ldots$ & $2.11 \pm 0.11$ & -1.37 \\
\hline 3894.04 & 33423.79 & $\mathrm{z}^{5} \mathrm{D}^{o}$ & 1 & 7750.78 & $a^{5} \mathrm{D}$ & 0 & $\ldots$ & $3.28 \pm 0.17$ & -1.65 \\
\hline 3902.91 & 33542.11 & $\mathrm{z}^{5} \mathrm{D}^{o}$ & 2 & 7927.47 & $a^{5} \mathrm{D}$ & 2 & $\ldots$ & $2.66 \pm 0.13$ & -1.52 \\
\hline 3903.17 & 33423.79 & $\mathrm{z}^{5} \mathrm{D}^{o}$ & 1 & 7810.82 & $a^{5} \mathrm{D}$ & 1 & $\ldots$ & $0.85 \pm 0.05$ & -2.23 \\
\hline 3908.76 & 33671.55 & $\mathrm{z}^{5} \mathrm{D}^{o}$ & 3 & 8095.21 & $a^{5} D$ & 3 & $\ldots$ & $5.55 \pm 0.28$ & -1.05 \\
\hline 3916.25 & 33338.20 & $\mathrm{z}^{5} \mathrm{D}^{o}$ & 0 & 7810.82 & $a^{5} D$ & 1 & $\ldots$ & $7.7 \pm 0.4$ & -1.75 \\
\hline 3919.15 & 33816.06 & $\mathrm{z}^{5} \mathrm{D}^{o}$ & 4 & 8307.57 & $a^{5} \mathrm{D}$ & 4 & $\ldots$ & $9.4 \pm 0.5$ & -0.71 \\
\hline 3921.02 & 33423.79 & $\mathrm{z}^{5} \mathrm{D}^{o}$ & 1 & 7927.47 & $a^{5} D$ & 2 & $\ldots$ & $5.37 \pm 0.27$ & -1.43 \\
\hline 3928.64 & 33542.11 & $\mathrm{z}^{5} \mathrm{D}^{o}$ & 2 & 8095.21 & $a^{5} \mathrm{D}$ & 3 & $\ldots$ & $4.20 \pm 0.21$ & -1.31 \\
\hline 3941.48 & 33671.55 & $\mathrm{z}^{5} \mathrm{D}^{o}$ & 3 & 8307.57 & $a^{5} \mathrm{D}$ & 4 & $\ldots$ & $2.48 \pm 0.13$ & -1.39 \\
\hline
\end{tabular}


Table 3-Continued

\begin{tabular}{|c|c|c|c|c|c|c|c|c|c|}
\hline $\begin{array}{l}\lambda_{\text {air }} \\
{[\AA]}\end{array}$ & $\begin{array}{l}\mathrm{E}_{\text {upper }} \\
{\left[\mathrm{cm}^{-1}\right]}\end{array}$ & Term & $\mathrm{J}_{\text {upper }}$ & $\begin{array}{l}\mathrm{E}_{\text {lower }} \\
{\left[\mathrm{cm}^{-1}\right]}\end{array}$ & Term & $\mathrm{J}_{\text {lower }}$ & $\begin{array}{c}\mathrm{A}_{\text {LScalc }} \\
{\left[10^{6} \mathrm{~s}^{-1}\right]}\end{array}$ & $\begin{array}{c}\mathrm{A}_{\operatorname{Exp}} \\
{\left[10^{6} \mathrm{~s}^{-1}\right]}\end{array}$ & $\log g f$ \\
\hline 3963.69 & 45741.49 & $\mathrm{y}^{5} \mathrm{H}^{o}$ & 7 & 20519.60 & $a^{5} \mathrm{G}$ & 6 & 112 & $118 \pm 6$ & 0.62 \\
\hline 3969.06 & 45707.36 & $\mathrm{y}^{5} \mathrm{H}^{o}$ & 6 & 20519.60 & $a^{5} \mathrm{G}$ & 6 & 7.4 & $6.9 \pm 0.4$ & -0.67 \\
\hline 3969.74 & 45707.36 & $\mathrm{y}^{5} \mathrm{H}^{o}$ & 6 & 20523.94 & $a^{5} \mathrm{G}$ & 5 & 104 & $105 \pm 5$ & 0.51 \\
\hline 3976.66 & 45663.28 & $\mathrm{y}^{5} \mathrm{H}^{o}$ & 5 & 20523.69 & $a^{5} \mathrm{G}$ & 4 & 98 & $93 \pm 5$ & 0.39 \\
\hline 3976.70 & 45663.28 & $\mathrm{y}^{5} \mathrm{H}^{o}$ & 5 & 20523.94 & $a^{5} \mathrm{G}$ & 5 & 12.8 & $12.7 \pm 1.1$ & -0.48 \\
\hline 3983.90 & 45614.88 & $\mathrm{y}^{5} \mathrm{H}^{o}$ & 4 & 20520.92 & $a^{5} \mathrm{G}$ & 3 & N 94 & $94 \pm 5$ & 0.30 \\
\hline 3984.34 & 45614.88 & $\mathrm{y}^{5} \mathrm{H}^{o}$ & 4 & 20523.69 & $a^{5} G$ & 4 & 15.4 & $15.8 \pm 1.1$ & -0.47 \\
\hline 3991.11 & 45566.02 & $\mathrm{y}^{5} \mathrm{H}^{o}$ & 3 & 20517.40 & $a^{5} \mathrm{G}$ & 2 & 95 & $100 \pm 5$ & 0.22 \\
\hline 3991.67 & 45566.02 & $\mathrm{y}^{5} \mathrm{H}^{o}$ & 3 & 20520.92 & $a^{5} \mathrm{G}$ & 3 & 13.4 & $13.8 \pm 0.8$ & -0.64 \\
\hline 4025.00 & 45358.63 & $\mathrm{z}^{3} \mathrm{H}^{o}$ & 4 & 20520.92 & $a^{5} \mathrm{G}$ & 3 & $\ldots$ & $4.0 \pm 0.4$ & -1.05 \\
\hline 4025.45 & 45358.63 & $\mathrm{z}^{3} \mathrm{H}^{o}$ & 4 & 20523.69 & $a^{5} G$ & 4 & $\ldots$ & $0.61 \pm 0.13$ & -1.88 \\
\hline 4026.21 & 45354.18 & $\mathrm{z}^{3} \mathrm{H}^{o}$ & 5 & 20523.94 & $a^{5} \mathrm{G}$ & 5 & $\ldots$ & $0.45 \pm 0.06$ & -1.92 \\
\hline 4027.09 & 45348.73 & $\mathrm{z}^{3} \mathrm{H}^{o}$ & 6 & 20523.94 & $a^{5} G$ & 5 & $\ldots$ & $3.53 \pm 0.29$ & -0.95 \\
\hline 4254.33 & 23498.84 & $\mathrm{z}^{7} \mathrm{P}^{o}$ & 4 & 0.00 & $a^{7} S$ & 3 & $\ldots$ & $33.0 \pm 1.7$ & -0.09 \\
\hline 4261.35 & 46958.98 & $\mathrm{f}^{7} \mathrm{D}$ & 5 & 23498.84 & $\mathrm{z}^{7} \mathrm{P}^{o}$ & 4 & $\ldots$ & $6.8 \pm 0.5$ & -0.69 \\
\hline 4272.90 & 46783.06 & $\mathrm{f}^{7} \mathrm{D}$ & 4 & 23386.35 & $\mathrm{z}^{7} \mathrm{P}^{o}$ & 3 & $\ldots$ & $4.2 \pm 0.4$ & -0.98 \\
\hline 4274.80 & 23386.35 & $\mathrm{z}^{7} \mathrm{P}^{o}$ & 3 & 0.00 & $a^{7} S$ & 3 & $\ldots$ & $31.7 \pm 1.6$ & -0.22 \\
\hline 4284.72 & 46637.21 & $\mathrm{f}^{7} \mathrm{D}$ & 3 & 23305.01 & $\mathrm{z}^{7} \mathrm{P}^{o}$ & 2 & $\ldots$ & $2.6 \pm 0.4$ & -1.30 \\
\hline 4289.72 & 23305.01 & $\mathrm{z}^{7} \mathrm{P}^{o}$ & 2 & 0.00 & $a^{7} \mathrm{~S}$ & 3 & $\cdots$ & $31.0 \pm 1.5$ & -0.37 \\
\hline 4293.55 & 46783.06 & $\mathrm{f}^{7} \mathrm{D}$ & 4 & 23498.84 & $\mathrm{z}^{7} \mathrm{P}^{o}$ & 4 & $\ldots$ & $2.53 \pm 0.22$ & -1.20 \\
\hline 4299.71 & 46637.21 & $\mathrm{f}^{7} \mathrm{D}$ & 3 & 23386.35 & $\mathrm{z}^{7} \mathrm{P}^{o}$ & 3 & $\ldots$ & $4.7 \pm 0.4$ & -1.04 \\
\hline 4305.45 & 46524.84 & $\mathrm{f}^{7} \mathrm{D}$ & 2 & 23305.01 & $\mathrm{z}^{7} \mathrm{P}^{o}$ & 2 & $\ldots$ & $7.8 \pm 1.4$ & -0.97 \\
\hline 4319.64 & 46448.60 & $\mathrm{f}^{7} \mathrm{D}$ & 1 & 23305.01 & $\mathrm{z}^{7} \mathrm{P}^{o}$ & 2 & $\ldots$ & $8.6 \pm 1.1$ & -1.14 \\
\hline 4320.59 & 46524.84 & $f^{7} D$ & 2 & 23386.35 & $\mathrm{z}^{7} \mathrm{P}^{o}$ & 3 & $\ldots$ & $2.7 \pm 0.3$ & -1.42 \\
\hline 4320.61 & 46637.21 & $\mathrm{f}^{7} \mathrm{D}$ & 3 & 23498.84 & $\mathrm{z}^{7} \mathrm{P}^{o}$ & 4 & $\ldots$ & $0.52 \pm 0.12$ & -1.99 \\
\hline 4337.55 & 30858.82 & $\mathrm{z}^{5} \mathrm{~F}^{o}$ & 2 & 7810.82 & $a^{5} \mathrm{D}$ & 1 & 5.65 & $5.75 \pm 0.29$ & -1.09 \\
\hline 4339.44 & 30965.46 & $\mathrm{z}^{5} \mathrm{~F}^{o}$ & 3 & 7927.47 & $a^{5} \mathrm{D}$ & 2 & N 6.9 & $6.9 \pm 0.3$ & -0.86 \\
\hline 4339.71 & 30787.30 & $\mathrm{z}^{5} \mathrm{~F}^{o}$ & 1 & 7750.78 & $a^{5} \mathrm{D}$ & 0 & 4.70 & $4.66 \pm 0.23$ & -1.40 \\
\hline 4344.50 & 31106.37 & $\mathrm{z}^{5} \mathrm{~F}^{o}$ & 4 & 8095.21 & $a^{5} \mathrm{D}$ & 3 & 8.4 & $8.7 \pm 0.4$ & -0.65 \\
\hline
\end{tabular}


Table 3-Continued

\begin{tabular}{|c|c|c|c|c|c|c|c|c|c|}
\hline $\begin{array}{l}\lambda_{\text {air }} \\
{[\AA]}\end{array}$ & $\begin{array}{l}\mathrm{E}_{\text {upper }} \\
{\left[\mathrm{cm}^{-1}\right]}\end{array}$ & Term & $\mathrm{J}_{\text {upper }}$ & $\begin{array}{l}\mathrm{E}_{\text {lower }} \\
{\left[\mathrm{cm}^{-1}\right]}\end{array}$ & Term & $\mathrm{J}_{\text {lower }}$ & $\begin{array}{l}\mathrm{A}_{\text {LScalc }} \\
{\left[10^{6} \mathrm{~s}^{-1}\right]}\end{array}$ & $\begin{array}{c}\mathrm{A}_{\operatorname{Exp}} \\
{\left[10^{6} \mathrm{~S}^{-1}\right]}\end{array}$ & $\log g f$ \\
\hline 4351.05 & 30787.30 & $\mathrm{z}^{5} \mathrm{~F}^{o}$ & 1 & 7810.82 & $a^{5} \mathrm{D}$ & 1 & 4.67 & $4.40 \pm 0.22$ & -1.43 \\
\hline 4351.75 & 31280.35 & $\mathrm{z}^{5} \mathrm{~F}^{o}$ & 5 & 8307.57 & $a^{5} \mathrm{D}$ & 4 & 10.0 & $10.6 \pm 0.5$ & -0.48 \\
\hline 4356.75 & 47228.80 & $\mathrm{x}^{5} \mathrm{G}^{o}$ & 5 & 24282.34 & $b^{5} \mathrm{D}$ & 4 & & $2.19 \pm 0.18$ & -1.16 \\
\hline 4359.62 & 30858.82 & $\mathrm{z}^{5} \mathrm{~F}^{o}$ & 2 & 7927.47 & $a^{5} \mathrm{D}$ & 2 & 3.98 & $3.74 \pm 0.19$ & -1.27 \\
\hline 4364.15 & 47189.87 & $\mathrm{x}^{5} \mathrm{G}^{o}$ & 4 & 24282.34 & $b^{5} \mathrm{D}$ & 4 & $\ldots$ & $0.39 \pm 0.07$ & -1.99 \\
\hline 4368.27 & 47189.87 & $\mathrm{x}^{5} \mathrm{G}^{o}$ & 4 & 24303.94 & $b^{5} \mathrm{D}$ & 3 & $\ldots$ & $1.96 \pm 0.18$ & -1.30 \\
\hline 4371.26 & 30965.46 & $\mathrm{z}^{5} \mathrm{~F}^{o}$ & 3 & 8095.21 & $a^{5} \mathrm{D}$ & 3 & 2.96 & $2.70 \pm 0.14$ & -1.27 \\
\hline 4373.26 & 30787.30 & $\mathrm{z}^{5} \mathrm{~F}^{o}$ & 1 & 7927.47 & $a^{5} \mathrm{D}$ & 2 & 0.66 & $0.58 \pm 0.04$ & -2.30 \\
\hline 4384.96 & 31106.37 & $\mathrm{z}^{5} \mathrm{~F}^{o}$ & 4 & 8307.57 & $a^{5} \mathrm{D}$ & 4 & 1.63 & $1.51 \pm 0.08$ & -1.41 \\
\hline 4391.74 & 30858.82 & $\mathrm{z}^{5} \mathrm{~F}^{o}$ & 2 & 8095.21 & $a^{5} \mathrm{D}$ & 3 & 0.389 & $0.326 \pm 0.018$ & -2.33 \\
\hline 4412.23 & 30965.46 & $\mathrm{z}^{5} \mathrm{~F}^{o}$ & 3 & 8307.57 & $a^{5} \mathrm{D}$ & 4 & 0.137 & $0.105 \pm 0.006$ & -2.67 \\
\hline 4496.84 & 29824.75 & $\mathrm{y}^{5} \mathrm{P}^{o}$ & 3 & 7593.16 & $a^{5} \mathrm{~S}$ & 2 & $\ldots$ & $3.38 \pm 0.18$ & -1.14 \\
\hline 4526.44 & 42605.81 & $\mathrm{z}^{5} \mathrm{G}^{o}$ & 6 & 20519.60 & $a^{5} G$ & 6 & $\ldots$ & $17.7 \pm 0.9$ & -0.15 \\
\hline 4527.33 & 42605.81 & $\mathrm{z}^{5} \mathrm{G}^{\circ}$ & 6 & 20523.94 & $a^{5} \mathrm{G}$ & 5 & $\ldots$ & $2.12 \pm 0.11$ & -1.07 \\
\hline 4529.84 & 42589.25 & $\mathrm{z}^{5} \mathrm{G}^{\circ}$ & 5 & 20519.60 & $a^{5} \mathrm{G}$ & 6 & $\ldots$ & $1.31 \pm 0.09$ & -1.35 \\
\hline 4530.68 & 42589.25 & $\mathrm{z}^{5} \mathrm{G}^{\circ}$ & 5 & 20523.69 & $a^{5} \mathrm{G}$ & 4 & $\ldots$ & $3.11 \pm 0.27$ & -0.98 \\
\hline 4530.73 & 42589.25 & $\mathrm{z}^{5} \mathrm{G}^{o}$ & 5 & 20523.94 & $a^{5} \mathrm{G}$ & 5 & $\ldots$ & $16.0 \pm 0.8$ & -0.27 \\
\hline 4535.12 & 42564.85 & $\mathrm{z}^{5} \mathrm{G}^{\circ}$ & 4 & 20520.92 & $a^{5} \mathrm{G}$ & 3 & $\ldots$ & $3.48 \pm 0.20$ & -1.02 \\
\hline 4535.69 & 42564.85 & $\mathrm{z}^{5} \mathrm{G}^{\circ}$ & 4 & 23.69 & $a^{5} \mathrm{G}$ & 4 & $\ldots$ & $13.8=$ & -0.42 \\
\hline 4535.75 & 42564.85 & $\mathrm{z}^{5} \mathrm{G}^{o}$ & 4 & 20523.94 & $a^{5} \mathrm{G}$ & 5 & $\ldots$ & $2.33 \pm 0.14$ & -1.19 \\
\hline 4539.76 & 42538.81 & $\mathrm{z}^{5} \mathrm{G}^{o}$ & 3 & 20517.40 & $a^{5} \mathrm{G}$ & 2 & $\ldots$ & $2.96 \pm 0.16$ & -1.19 \\
\hline 4540.49 & 42538.81 & $\mathrm{z}^{5} \mathrm{G}^{\circ}$ & 3 & 20520.92 & $a^{5} \mathrm{G}$ & 3 & $\ldots$ & $14.0 \pm 0.7$ & -0.52 \\
\hline 4541.06 & 42538.81 & $\mathrm{z}^{5} \mathrm{G}^{\circ}$ & 3 & 20523.69 & $a^{5} \mathrm{G}$ & 4 & $\ldots$ & $3.25 \pm 0.18$ & -1.15 \\
\hline 4544.60 & 42515.35 & $\mathrm{z}^{5} \mathrm{G}^{\circ}$ & 2 & 20517.40 & $a^{5} \mathrm{G}$ & 2 & $\ldots$ & $16.6 \pm 0.9$ & -0.59 \\
\hline 4545.33 & 42515.35 & $\mathrm{z}^{5} \mathrm{G}^{\circ}$ & 2 & 20520.92 & $a^{5} \mathrm{G}$ & 3 & $\ldots$ & $3.21 \pm 0.18$ & -1.30 \\
\hline 4545.95 & 29584.62 & $\mathrm{y}^{5} \mathrm{P}^{o}$ & 2 & 7593.16 & $a^{5} \mathrm{~S}$ & 2 & $\ldots$ & $2.75 \pm 0.14$ & -1.37 \\
\hline 4565.50 & 29824.75 & $\mathrm{y}^{5} \mathrm{P}^{o}$ & 3 & 7927.47 & $a^{5} \mathrm{D}$ & 2 & 0.306 & $0.432 \pm 0.028$ & -2.02 \\
\hline 4580.04 & 29420.90 & $\mathrm{y}^{5} \mathrm{P}^{o}$ & 1 & 7593.16 & $a^{5} S$ & 2 & $\cdots$ & $2.34 \pm 0.12$ & -1.66 \\
\hline 4591.39 & 29584.62 & $\mathrm{y}^{5} \mathrm{P}^{o}$ & 2 & 7810.82 & $a^{5} D$ & 1 & 0.95 & $1.16 \pm 0.06$ & -1.74 \\
\hline
\end{tabular}


Table 3-Continued

\begin{tabular}{|c|c|c|c|c|c|c|c|c|c|}
\hline $\begin{array}{l}\lambda_{\text {air }} \\
{[\AA]}\end{array}$ & $\begin{array}{l}\mathrm{E}_{\text {upper }} \\
{\left[\mathrm{cm}^{-1}\right]}\end{array}$ & Term & $\mathrm{J}_{\text {upper }}$ & $\begin{array}{l}\mathrm{E}_{\text {lower }} \\
{\left[\mathrm{cm}^{-1}\right]}\end{array}$ & Term & $\mathrm{J}_{\text {lower }}$ & $\begin{array}{l}\mathrm{A}_{\text {LScalc }} \\
{\left[10^{6} \mathrm{~s}^{-1}\right]}\end{array}$ & $\begin{array}{c}\mathrm{A}_{\operatorname{Exp}} \\
{\left[10^{6} \mathrm{~s}^{-1}\right]}\end{array}$ & $\log g f$ \\
\hline 4600.74 & 29824.75 & $\mathrm{y}^{5} \mathrm{P}^{o}$ & 3 & 8095.21 & $a^{5} \mathrm{D}$ & 3 & 2.10 & $2.52 \pm 0.14$ & -1.25 \\
\hline 4613.36 & 29420.90 & $\mathrm{y}^{5} \mathrm{P}^{o}$ & 1 & 7750.78 & $a^{5} \mathrm{D}$ & 0 & 2.08 & $2.31 \pm 0.12$ & -1.65 \\
\hline 4616.12 & 29584.62 & $\mathrm{y}^{5} \mathrm{P}^{o}$ & 2 & 7927.47 & $a^{5} \mathrm{D}$ & 2 & 3.63 & $4.02 \pm 0.20$ & -1.19 \\
\hline 4626.17 & 29420.90 & $\mathrm{y}^{5} \mathrm{P}^{o}$ & 1 & 7810.82 & $a^{5} D$ & 1 & 4.64 & $4.85 \pm 0.24$ & -1.33 \\
\hline 4628.47 & 46958.98 & $\mathrm{f}^{7} \mathrm{D}$ & 5 & 25359.62 & $\mathrm{z}^{7} \mathrm{~F}^{o}$ & 4 & 0.80 & $1.13 \pm 0.15$ & -1.40 \\
\hline 4633.26 & 46783.06 & $\mathrm{f}^{7} \mathrm{D}$ & 4 & 25206.02 & $\mathrm{z}^{7} \mathrm{~F}^{o}$ & 3 & 2.44 & $2.7 \pm 0.3$ & -1.11 \\
\hline 4639.50 & 46637.21 & $\mathrm{f}^{7} \mathrm{D}$ & 3 & 25089.20 & $\mathrm{z}^{7} \mathrm{~F}^{o}$ & 2 & 5.0 & $5.5 \pm 0.4$ & -0.91 \\
\hline 4646.15 & 29824.75 & $\mathrm{y}^{5} \mathrm{P}^{o}$ & 3 & 8307.57 & $a^{5} \mathrm{D}$ & 4 & 7.9 & $8.0 \pm 0.4$ & -0.74 \\
\hline 4646.79 & 46524.84 & $\mathrm{f}^{7} \mathrm{D}$ & 2 & 25010.64 & $z^{7} F^{o}$ & 1 & 8.7 & $8.9 \pm 0.8$ & -0.84 \\
\hline 4651.28 & 29420.90 & $\mathrm{y}^{5} \mathrm{P}^{o}$ & 1 & 7927.47 & $a^{5} D$ & 2 & 3.55 & $3.56 \pm 0.18$ & -1.46 \\
\hline 4652.15 & 29584.62 & $\mathrm{y}^{5} \mathrm{P}^{o}$ & 2 & 8095.21 & $a^{5} \mathrm{D}$ & 3 & N 5.68 & $5.68 \pm 0.29$ & -1.04 \\
\hline 4654.76 & 46448.60 & $\mathrm{f}^{7} \mathrm{D}$ & 1 & 24971.21 & $\mathrm{z}^{7} \mathrm{~F}^{o}$ & 0 & 14.5 & $14.7 \pm 0.9$ & -0.84 \\
\hline 4663.32 & 46448.60 & $\mathrm{f}^{7} \mathrm{D}$ & 1 & 25010.64 & $\mathrm{z}^{7} \mathrm{~F}^{o}$ & 1 & 28.8 & $27.9 \pm 1.7$ & -0.56 \\
\hline 4663.82 & 46524.84 & $\mathrm{f}^{7} \mathrm{D}$ & 2 & 25089.20 & $\mathrm{z}^{7} \mathrm{~F}^{o}$ & 2 & 25.9 & $24.7 \pm 1.4$ & -0.39 \\
\hline 4664.79 & 46637.21 & $\mathrm{f}^{7} \mathrm{D}$ & 3 & 25206.02 & $\mathrm{z}^{7} \mathrm{~F}^{o}$ & 3 & 21.5 & $21.8 \pm 1.2$ & -0.30 \\
\hline 4666.20 & 45358.63 & $\mathrm{z}^{3} \mathrm{H}^{o}$ & 4 & 23933.90 & $a^{3} \mathrm{H}$ & 4 & $\ldots$ & $4.44 \pm 0.24$ & -0.88 \\
\hline 4666.48 & 46783.06 & $\mathrm{f}^{7} \mathrm{D}$ & 4 & 25359.62 & $\mathrm{z}^{7} \mathrm{~F}^{o}$ & 4 & 15.8 & $15.5 \pm 0.9$ & -0.34 \\
\hline 4667.17 & 45354.18 & $\mathrm{z}^{3} \mathrm{H}^{o}$ & 5 & 23933.90 & $\mathrm{a}^{3} \mathrm{H}$ & 4 & $\ldots$ & $1.55 \pm 0.11$ & -1.25 \\
\hline 4669.33 & 46958.98 & $\mathrm{f}^{7} \mathrm{D}$ & 5 & 25548.64 & $\mathrm{z}^{7} \mathrm{~F}^{o}$ & 5 & 8.6 & $9.4 \pm 0.6$ & -0.47 \\
\hline 4680.47 & 46448.60 & $f^{7} D$ & 1 & 25089.20 & $\mathrm{z}^{7} \mathrm{~F}^{o}$ & 2 & 17.1 & $17.3 \pm 1.1$ & -0.77 \\
\hline 4689.38 & 46524.84 & $\mathrm{f}^{7} \mathrm{D}$ & 2 & 25206.02 & $\mathrm{z}^{7} \mathrm{~F}^{o}$ & 3 & 25.4 & $24.0 \pm 1.4$ & -0.40 \\
\hline 4692.97 & 45358.63 & $\mathrm{z}^{3} \mathrm{H}^{o}$ & 4 & 24056.11 & $\mathrm{a}^{3} \mathrm{H}$ & 5 & $\ldots$ & $0.24 \pm 0.04$ & -2.15 \\
\hline 4693.95 & 45354.18 & $\mathrm{z}^{3} \mathrm{H}^{o}$ & 5 & 24056.11 & $a^{3} \mathrm{H}$ & 5 & $\ldots$ & $4.35 \pm 0.24$ & -0.80 \\
\hline 4695.15 & 45348.73 & $\mathrm{z}^{3} \mathrm{H}^{o}$ & 6 & 24056.11 & $a^{3} \mathrm{H}$ & 5 & $\ldots$ & $1.78 \pm 0.10$ & -1.12 \\
\hline 4698.47 & 46637.21 & $\mathrm{f}^{7} \mathrm{D}$ & 3 & 25359.62 & $z^{7} F^{o}$ & 4 & N 33.1 & $33.1 \pm 1.8$ & -0.11 \\
\hline 4708.02 & 46783.06 & $\mathrm{f}^{7} \mathrm{D}$ & 4 & 25548.64 & $\mathrm{z}^{7} \mathrm{~F}^{o}$ & 5 & 41.0 & $39.0 \pm 2.1$ & 0.07 \\
\hline 4718.43 & 46958.98 & $\mathrm{f}^{7} \mathrm{D}$ & 5 & 25771.40 & $\mathrm{z}^{7} \mathrm{~F}^{o}$ & 6 & 49.2 & $47.3 \pm 2.5$ & 0.24 \\
\hline 4727.15 & 45348.73 & $\mathrm{z}^{3} \mathrm{H}^{o}$ & 6 & 24200.23 & $\mathrm{a}^{3} \mathrm{H}$ & 6 & 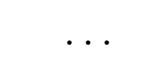 & $5.2 \pm 0.3$ & -0.65 \\
\hline 4745.27 & 42908.57 & $\mathrm{x}^{5} \mathrm{D}^{o}$ & 4 & 21840.84 & $a^{5} \mathrm{P}$ & 3 & $\ldots$ & $1.39 \pm 0.22$ & -1.38 \\
\hline
\end{tabular}


Table 3-Continued

\begin{tabular}{|c|c|c|c|c|c|c|c|c|c|}
\hline $\begin{array}{l}\lambda_{\text {air }} \\
{[\AA]}\end{array}$ & $\begin{array}{l}\mathrm{E}_{\text {upper }} \\
{\left[\mathrm{cm}^{-1}\right]}\end{array}$ & Term & $\mathrm{J}_{\text {upper }}$ & $\begin{array}{l}\mathrm{E}_{\text {lower }} \\
{\left[\mathrm{cm}^{-1}\right]}\end{array}$ & Term & $\mathrm{J}_{\text {lower }}$ & $\begin{array}{l}\mathrm{A}_{\text {LScalc }} \\
{\left[10^{6} \mathrm{~s}^{-1}\right]}\end{array}$ & $\begin{array}{c}\mathrm{A}_{\operatorname{Exp}} \\
{\left[10^{6} \mathrm{~s}^{-1}\right]}\end{array}$ & $\log g f$ \\
\hline 4789.34 & 41393.47 & $\mathrm{y}^{5} \mathrm{~F}^{o}$ & 5 & 20519.60 & $a^{5} G$ & 6 & $\ldots$ & $12.4 \pm 1.6$ & -0.33 \\
\hline 4790.34 & 41393.47 & $\mathrm{y}^{5} \mathrm{~F}^{o}$ & 5 & 20523.94 & $a^{5} \mathrm{G}$ & 5 & $\ldots$ & $0.88 \pm 0.13$ & -1.48 \\
\hline 4814.28 & 45663.28 & $\mathrm{y}^{5} \mathrm{H}^{o}$ & 5 & 24897.55 & $a^{3} G$ & 4 & $\ldots$ & $1.57 \pm 0.14$ & -1.22 \\
\hline 4829.31 & 41224.78 & $\mathrm{y}^{5} \mathrm{~F}^{o}$ & 4 & 20523.69 & $a^{5} \mathrm{G}$ & 4 & $\ldots$ & $1.22 \pm 0.19$ & -1.42 \\
\hline 4829.37 & 41224.78 & $\mathrm{y}^{5} \mathrm{~F}^{o}$ & 4 & 20523.94 & $a^{5} \mathrm{G}$ & 5 & $\ldots$ & $9.8 \pm 1.4$ & -0.51 \\
\hline 4836.87 & 45707.36 & $\mathrm{y}^{5} \mathrm{H}^{o}$ & 6 & 25038.61 & $a^{3} G$ & 5 & $\ldots$ & $1.8 \pm 0.3$ & -1.09 \\
\hline 4847.21 & 45663.28 & $\mathrm{y}^{5} \mathrm{H}^{o}$ & 5 & 25038.61 & $a^{3} G$ & 5 & $\ldots$ & $0.29 \pm 0.05$ & -1.95 \\
\hline 4861.19 & 41086.26 & $\mathrm{y}^{5} \mathrm{~F}^{o}$ & 3 & 20520.92 & $a^{5} \mathrm{G}$ & 3 & $\ldots$ & $1.43 \pm 0.23$ & -1.45 \\
\hline 4861.85 & 41086.26 & $\mathrm{y}^{5} \mathrm{~F}^{o}$ & 3 & 20523.69 & $a^{5} \mathrm{G}$ & 4 & $\ldots$ & $7.7 \pm 1.1$ & -0.72 \\
\hline 4870.80 & 45358.63 & $\mathrm{z}^{3} \mathrm{H}^{o}$ & 4 & 24833.86 & $a^{3} G$ & 3 & $\ldots$ & $30.2 \pm 1.5$ & -0.01 \\
\hline 4880.05 & 45663.28 & $\mathrm{y}^{5} \mathrm{H}^{o}$ & 5 & 25177.39 & $a^{3} \mathrm{~F}$ & 4 & $\ldots$ & $0.67 \pm 0.15$ & -1.58 \\
\hline 4885.96 & 45358.63 & $\mathrm{z}^{3} \mathrm{H}^{o}$ & 4 & 24897.55 & $a^{3} G$ & 4 & $\ldots$ & $2.33 \pm 0.14$ & -1.12 \\
\hline 4887.03 & 45354.18 & $\mathrm{z}^{3} \mathrm{H}^{o}$ & 5 & 24897.55 & $a^{3} \mathrm{G}$ & 4 & $\ldots$ & $30.6 \pm 1.6$ & 0.08 \\
\hline 4887.68 & 40971.29 & $\mathrm{y}^{5} \mathrm{~F}^{o}$ & 2 & 20517.40 & $a^{5} \mathrm{G}$ & 2 & $\ldots$ & $0.48 \pm 0.09$ & -2.07 \\
\hline 4888.52 & 40971.29 & $\mathrm{y}^{5} \mathrm{~F}^{o}$ & 2 & 20520.92 & $a^{5} \mathrm{G}$ & 3 & $\ldots$ & $2.4 \pm 0.4$ & -1.36 \\
\hline 4903.22 & 40906.46 & $\mathrm{y}^{5} \mathrm{~F}^{o}$ & 1 & 20517.40 & $a^{5} G$ & 2 & $\ldots$ & $7.7 \pm 1.3$ & -1.08 \\
\hline 4920.96 & 45354.18 & $\mathrm{z}^{3} \mathrm{H}^{o}$ & 5 & 25038.61 & $a^{3} G$ & 5 & $\ldots$ & $2.98 \pm 0.16$ & -0.92 \\
\hline 4922.28 & 45348.73 & $\mathrm{z}^{3} \mathrm{H}^{o}$ & 6 & 25038.61 & $a^{3} G$ & 5 & $\ldots$ & $50.2 \pm 2.5$ & 0.38 \\
\hline 4936.34 & 45358.63 & $\mathrm{z}^{3} \mathrm{H}^{o}$ & 4 & 25106.34 & $a^{3} \mathrm{~F}$ & 3 & $\cdots$ & $16.9 \pm 0.9$ & -0.25 \\
\hline 4953.71 & 45358.63 & $\mathrm{z}^{3} \mathrm{H}^{o}$ & 4 & 25177.39 & $a^{3} \mathrm{~F}$ & 4 & $\ldots$ & $0.99 \pm 0.07$ & -1.48 \\
\hline 4954.81 & 45354.18 & $\mathrm{z}^{3} \mathrm{H}^{o}$ & 5 & 25177.39 & $a^{3} \mathrm{~F}$ & 4 & $\ldots$ & $16.6 \pm 0.9$ & -0.17 \\
\hline 5013.31 & 41782.19 & $\mathrm{y}^{5} \mathrm{D}^{o}$ & 4 & 21840.84 & $a^{5} \mathrm{P}$ & 3 & $\ldots$ & $5.0 \pm 0.8$ & -0.77 \\
\hline 5065.92 & 41575.10 & $\mathrm{y}^{5} \mathrm{D}^{o}$ & 3 & 21840.84 & $a^{5} \mathrm{P}$ & 3 & $\ldots$ & $1.55 \pm 0.25$ & -1.38 \\
\hline 5067.72 & 41575.10 & $\mathrm{y}^{5} \mathrm{D}^{o}$ & 3 & 21847.88 & $a^{5} \mathrm{P}$ & 2 & $\ldots$ & $3.2 \pm 0.5$ & -1.07 \\
\hline 5110.75 & 41409.03 & $\mathrm{y}^{5} \mathrm{D}^{o}$ & 2 & 21847.88 & $a^{5} \mathrm{P}$ & 2 & $\ldots$ & $2.4 \pm 0.4$ & -1.32 \\
\hline 5113.12 & 41409.03 & $\mathrm{y}^{5} \mathrm{D}^{o}$ & 2 & 21856.94 & $a^{5} \mathrm{P}$ & 1 & $\ldots$ & $1.70 \pm 0.27$ & -1.48 \\
\hline 5142.26 & 41289.17 & $\mathrm{y}^{5} \mathrm{D}^{o}$ & 1 & 21847.88 & $a^{5} \mathrm{P}$ & 2 & $\ldots$ & $0.96 \pm 0.19$ & -1.94 \\
\hline 5144.66 & 41289.17 & $\mathrm{y}^{5} \mathrm{D}^{o}$ & 1 & 21856.94 & $a^{5} \mathrm{P}$ & 1 & $\ldots$ & $3.5 \pm 0.6$ & -1.37 \\
\hline 5177.42 & 46958.98 & $\mathrm{f}^{7} \mathrm{D}$ & 5 & 27649.71 & $\mathrm{z}^{7} \mathrm{D}^{o}$ & 4 & 6.6 & $6.7 \pm 0.6$ & -0.53 \\
\hline
\end{tabular}


Table 3-Continued

\begin{tabular}{|c|c|c|c|c|c|c|c|c|c|}
\hline $\begin{array}{l}\lambda_{\text {air }} \\
{[\AA]}\end{array}$ & $\begin{array}{l}\mathrm{E}_{\text {upper }} \\
{\left[\mathrm{cm}^{-1}\right]}\end{array}$ & Term & $\mathrm{J}_{\text {upper }}$ & $\begin{array}{l}\mathrm{E}_{\text {lower }} \\
{\left[\mathrm{cm}^{-1}\right]}\end{array}$ & Term & $\mathrm{J}_{\text {lower }}$ & $\begin{array}{c}\mathrm{A}_{L S c a l c} \\
{\left[10^{6} \mathrm{~S}^{-1}\right]}\end{array}$ & $\begin{array}{c}\mathrm{A}_{\operatorname{Exp}} \\
{\left[10^{6} \mathrm{~s}^{-1}\right]}\end{array}$ & $\log g f$ \\
\hline 5184.55 & 46783.06 & $f^{7} D$ & 4 & 27500.37 & $\mathrm{z}^{7} \mathrm{D}^{o}$ & 3 & 11.4 & $11.3 \pm 0.7$ & -0.39 \\
\hline 5192.00 & 46637.21 & $\mathrm{f}^{7} \mathrm{D}$ & 3 & 27382.18 & $\mathrm{z}^{7} \mathrm{D}^{o}$ & 2 & N 14.0 & $14.0 \pm 0.9$ & -0.40 \\
\hline 5200.21 & 46524.84 & $\mathrm{f}^{7} \mathrm{D}$ & 2 & 27300.19 & $\mathrm{z}^{7} \mathrm{D}^{o}$ & 1 & 13.0 & $13.0 \pm 0.9$ & -0.58 \\
\hline 5204.51 & 26801.93 & $\mathrm{z}^{5} \mathrm{P}^{o}$ & 1 & 7593.16 & $a^{5} \mathrm{~S}$ & 2 & $\ldots$ & $52.4 \pm 2.6$ & -0.19 \\
\hline 5206.04 & 26796.28 & $\mathrm{z}^{5} \mathrm{P}^{o}$ & 2 & 7593.16 & $a^{5} \mathrm{~S}$ & 2 & $\ldots$ & $51.9 \pm 2.6$ & 0.02 \\
\hline 5208.42 & 26787.50 & $\mathrm{z}^{5} \mathrm{P}^{o}$ & 3 & 7593.16 & $a^{5} S$ & 2 & $\ldots$ & $52.1 \pm 2.6$ & 0.17 \\
\hline 5220.91 & 46448.60 & $\mathrm{f}^{7} \mathrm{D}$ & 1 & 27300.19 & $\mathrm{z}^{7} \mathrm{D}^{o}$ & 1 & 10.7 & $10.6 \pm 0.7$ & -0.89 \\
\hline 5224.07 & 46637.21 & $\mathrm{f}^{7} \mathrm{D}$ & 3 & & $\mathrm{z}^{7} \mathrm{D}^{o}$ & 3 & 4.0 & & -0.87 \\
\hline 5224.97 & 46958.98 & $f^{7} D$ & 5 & 27825.45 & $\mathrm{z}^{7} \mathrm{D}^{o}$ & 5 & 25.6 & $26.0 \pm 1.5$ & 0.07 \\
\hline 5225.02 & 46783.06 & $\mathrm{f}^{7} \mathrm{D}$ & 4 & 27649.71 & $\mathrm{z}^{7} \mathrm{D}^{o}$ & 4 & 13.0 & $13.6 \pm 0.9$ & -0.30 \\
\hline 5225.81 & 40971.29 & $\mathrm{y}^{5} \mathrm{~F}^{o}$ & 2 & 21840.84 & $a^{5} \mathrm{P}$ & 3 & $\ldots$ & $1.54 \pm 0.24$ & -1.50 \\
\hline 5227.74 & 40971.29 & $\mathrm{y}^{5} \mathrm{~F}^{o}$ & 2 & 21847.88 & $a^{5} \mathrm{P}$ & 2 & $\ldots$ & $0.43 \pm 0.07$ & -2.05 \\
\hline 5230.22 & 40971.29 & $\mathrm{y}^{5} \mathrm{~F}^{o}$ & 2 & 21856.94 & $a^{5} \mathrm{P}$ & 1 & $\ldots$ & $0.92 \pm 0.15$ & -1.73 \\
\hline 5238.96 & 40930.31 & $\mathrm{x}^{5} \mathrm{P}^{o}$ & 1 & 21847.88 & $a^{5} \mathrm{P}$ & 2 & $\ldots$ & $4.3 \pm 0.7$ & -1.27 \\
\hline 5241.45 & 40930.31 & $\mathrm{x}^{5} \mathrm{P}^{o}$ & 1 & 21856.94 & $a^{5} \mathrm{P}$ & 1 & $\ldots$ & $0.97 \pm 0.22$ & -1.92 \\
\hline 5243.36 & 46448.60 & $\mathrm{f}^{7} \mathrm{D}$ & 1 & 27382.18 & $\mathrm{z}^{7} \mathrm{D}^{o}$ & 2 & 21.1 & $21.3 \pm 1.3$ & -0.58 \\
\hline 5247.57 & 26801.93 & $\mathrm{z}^{5} \mathrm{P}^{o}$ & 1 & 7750.78 & $a^{5} \mathrm{D}$ & 0 & 2.03 & $2.07 \pm 0.11$ & -1.59 \\
\hline 5254.93 & 46524.84 & $\mathrm{f}^{7} \mathrm{D}$ & 2 & 27500.37 & $\mathrm{z}^{7} \mathrm{D}^{o}$ & 3 & 18.8 & $19.0 \pm 1.2$ & -0.41 \\
\hline 5255.13 & 46958.98 & $\mathrm{f}^{7} \mathrm{D}$ & 5 & 27935.26 & $\mathrm{y}^{7} \mathrm{P}^{o}$ & 4 & 16.3 & $17.6 \pm 1.2$ & -0.10 \\
\hline 5264.16 & 26801.93 & $\mathrm{z}^{5} \mathrm{P}^{o}$ & 1 & 7810.82 & $a^{5} \mathrm{D}$ & 1 & 4.52 & $4.53 \pm 0.23$ & -1.25 \\
\hline 5265.16 & 46637.21 & $\mathrm{f}^{7} \mathrm{D}$ & 3 & 27649.71 & $\mathrm{z}^{7} \mathrm{D}^{o}$ & 4 & 13.9 & $15.2 \pm 0.9$ & -0.35 \\
\hline 5265.72 & 26796.28 & $\mathrm{z}^{5} \mathrm{P}^{o}$ & 2 & 7810.82 & $a^{5} \mathrm{D}$ & 1 & 0.90 & $0.95 \pm 0.05$ & -1.71 \\
\hline 5272.01 & 46783.06 & $\mathrm{f}^{7} \mathrm{D}$ & 4 & 27820.23 & $\mathrm{y}^{7} \mathrm{P}^{o}$ & 3 & 10.1 & $10.2 \pm 0.8$ & -0.42 \\
\hline 5273.46 & 46783.06 & $\mathrm{f}^{7} \mathrm{D}$ & 4 & 27825.45 & $\mathrm{z}^{7} \mathrm{D}^{o}$ & 5 & 7.6 & $8.2 \pm 0.6$ & -0.51 \\
\hline 5287.20 & 46637.21 & $\mathrm{f}^{7} \mathrm{D}$ & 3 & 27728.87 & $\mathrm{y}^{7} \mathrm{P}^{o}$ & 2 & N 4.6 & $4.6 \pm 0.5$ & -0.87 \\
\hline 5296.69 & 26801.93 & $\mathrm{z}^{5} \mathrm{P}^{o}$ & 1 & 7927.47 & $a^{5} \mathrm{D}$ & 2 & 3.45 & $3.48 \pm 0.18$ & -1.36 \\
\hline 5298.28 & 26796.28 & $\mathrm{z}^{5} \mathrm{P}^{o}$ & 2 & 7927.47 & $a^{5} D$ & 2 & N 3.45 & $3.45 \pm 0.18$ & -1.14 \\
\hline 5300.74 & 26787.50 & $\mathrm{z}^{5} \mathrm{P}^{o}$ & 3 & 7927.47 & $a^{5} \mathrm{D}$ & 2 & 0.281 & $0.342 \pm 0.024$ & -2.00 \\
\hline 5304.18 & 46783.06 & $\mathrm{f}^{7} \mathrm{D}$ & 4 & 27935.26 & $\mathrm{y}^{7} \mathrm{P}^{o}$ & 4 & 5.9 & $5.7 \pm 0.5$ & -0.67 \\
\hline
\end{tabular}


Table 3-Continued

\begin{tabular}{|c|c|c|c|c|c|c|c|c|c|}
\hline $\begin{array}{l}\lambda_{\text {air }} \\
{[\AA]}\end{array}$ & $\begin{array}{l}\mathrm{E}_{\text {upper }} \\
{\left[\mathrm{cm}^{-1}\right]}\end{array}$ & Term & $\mathrm{J}_{\text {upper }}$ & $\begin{array}{l}\mathrm{E}_{\text {lower }} \\
{\left[\mathrm{cm}^{-1}\right]}\end{array}$ & Term & $\mathrm{J}_{\text {lower }}$ & $\begin{array}{l}\mathrm{A}_{\text {LScalc }} \\
{\left[10^{6} \mathrm{~S}^{-1}\right]}\end{array}$ & $\begin{array}{c}\mathrm{A}_{\operatorname{Exp}} \\
{\left[10^{6} \mathrm{~S}^{-1}\right]}\end{array}$ & $\log g f$ \\
\hline 5312.87 & 46637.21 & $\mathrm{f}^{7} \mathrm{D}$ & 3 & 27820.23 & $\mathrm{y}^{7} \mathrm{P}^{o}$ & 3 & 9.9 & $9.5 \pm 0.6$ & -0.55 \\
\hline 5318.81 & 46524.84 & $\mathrm{f}^{7} \mathrm{D}$ & 2 & 27728.87 & $\mathrm{y}^{7} \mathrm{P}^{o}$ & 2 & 10.5 & $10.0 \pm 0.7$ & -0.67 \\
\hline 5340.47 & 46448.60 & $\mathrm{f}^{7} \mathrm{D}$ & 1 & 27728.87 & $\mathrm{y}^{7} \mathrm{P}^{o}$ & 2 & 15.5 & $14.5 \pm 1.1$ & -0.73 \\
\hline 5344.79 & 46524.84 & $\mathrm{f}^{7} \mathrm{D}$ & 2 & 27820.23 & $\mathrm{y}^{7} \mathrm{P}^{o}$ & 3 & 5.2 & $4.8 \pm 0.3$ & -0.99 \\
\hline 5345.80 & 26796.28 & $\mathrm{z}^{5} \mathrm{P}^{o}$ & 2 & 8095.21 & $a^{5} \mathrm{D}$ & 3 & 5.37 & $5.23 \pm 0.27$ & -0.95 \\
\hline 5348.31 & 26787.50 & $\mathrm{z}^{5} \mathrm{P}^{o}$ & 3 & 8095.21 & $a^{5} D$ & 3 & 1.92 & $2.05 \pm 0.11$ & -1.21 \\
\hline 5409.77 & 26787.50 & $\mathrm{z}^{5} \mathrm{P}^{o}$ & 3 & 8307.57 & $a^{5} \mathrm{D}$ & 4 & 7.1 & $7.0 \pm 0.4$ & -0.67 \\
\hline 5628.62 & 45358.63 & $\mathrm{z}^{3} \mathrm{H}^{o}$ & 4 & 27597.22 & $b^{3} \mathrm{G}$ & 3 & $\ldots$ & $4.2 \pm 0.4$ & -0.74 \\
\hline 5664.04 & 45354.18 & $\mathrm{z}^{3} \mathrm{H}^{o}$ & 5 & 27703.84 & $b^{3} \mathrm{G}$ & 4 & $\ldots$ & $3.68 \pm 0.26$ & -0.71 \\
\hline 5702.32 & 45348.73 & $\mathrm{z}^{3} \mathrm{H}^{o}$ & 6 & 27816.88 & $b^{3} \mathrm{G}$ & 5 & $\ldots$ & $3.41 \pm 0.24$ & -0.67 \\
\hline 5712.75 & 41782.19 & $\mathrm{y}^{5} \mathrm{D}^{o}$ & 4 & 24282.34 & $b^{5} \mathrm{D}$ & 4 & $\ldots$ & $2.1 \pm 0.4$ & -1.03 \\
\hline 5719.81 & 41782.19 & $\mathrm{y}^{5} \mathrm{D}^{o}$ & 4 & 24303.94 & $b^{5} \mathrm{D}$ & 3 & $\ldots$ & $0.59 \pm 0.12$ & -1.58 \\
\hline 5781.16 & 41575.10 & $\mathrm{y}^{5} \mathrm{D}^{o}$ & 3 & 24282.34 & $b^{5} \mathrm{D}$ & 4 & $\ldots$ & $2.8 \pm 0.5$ & -1.00 \\
\hline 5787.04 & 41575.10 & $\mathrm{y}^{5} \mathrm{D}^{o}$ & 3 & 24299.89 & $b^{5} \mathrm{D}$ & 2 & $\ldots$ & $0.81 \pm 0.22$ & -1.55 \\
\hline 5788.39 & 41575.10 & $\mathrm{y}^{5} \mathrm{D}^{o}$ & 3 & 24303.94 & $b^{5} \mathrm{D}$ & 3 & $\ldots$ & $0.91 \pm 0.17$ & -1.49 \\
\hline 5838.65 & 41409.03 & $\mathrm{y}^{5} \mathrm{D}^{o}$ & 2 & 24286.54 & $b^{5} \mathrm{D}$ & 1 & $\ldots$ & $0.59 \pm 0.11$ & -1.82 \\
\hline 5844.59 & 41409.03 & $\mathrm{y}^{5} \mathrm{D}^{o}$ & 2 & 24303.94 & $b^{5} \mathrm{D}$ & 3 & $\ldots$ & $0.67 \pm 0.15$ & -1.77 \\
\hline 5876.54 & 41289.17 & $\mathrm{y}^{5} \mathrm{D}^{o}$ & 1 & 24277.06 & $b^{5} \mathrm{D}$ & 0 & $\ldots$ & $0.58 \pm 0.14$ & -2.05 \\
\hline 5884.43 & 41289.17 & $\mathrm{y}^{5} \mathrm{D}^{o}$ & 1 & 24299.89 & $b^{5} \mathrm{D}$ & 2 & $\ldots$ & $0.88 \pm 0.21$ & -1.86 \\
\hline 6313.22 & 47228.80 & $\mathrm{x}^{5} \mathrm{G}^{o}$ & 5 & 31393.40 & $a^{5} \mathrm{~F}$ & 5 & $\ldots$ & $0.25 \pm 0.05$ & -1.78 \\
\hline 6322.60 & 47189.87 & $\mathrm{x}^{5} \mathrm{G}^{o}$ & 4 & 31377.96 & $a^{5} \mathrm{~F}$ & 4 & $\ldots$ & $0.30 \pm 0.06$ & -1.80 \\
\hline 8917.13 & 42589.25 & $\mathrm{z}^{5} \mathrm{G}^{o}$ & 5 & 31377.96 & $a^{5} \mathrm{~F}$ & 4 & $\ldots$ & $0.106 \pm 0.017$ & -1.86 \\
\hline 9290.48 & 31280.35 & $\mathrm{z}^{5} \mathrm{~F}^{o}$ & 5 & 20519.60 & $a^{5} G$ & 6 & $\ldots$ & $0.29 \pm 0.04$ & -1.38 \\
\hline 9294.23 & 31280.35 & $\mathrm{z}^{5} \mathrm{~F}^{o}$ & 5 & 20523.94 & $a^{5} \mathrm{G}$ & 5 & $\ldots$ & $0.025 \pm 0.003$ & -2.45 \\
\hline 9446.81 & 31106.37 & $\mathrm{z}^{5} \mathrm{~F}^{o}$ & 4 & 20523.69 & $a^{5} G$ & 4 & $\ldots$ & $0.051 \pm 0.008$ & -2.21 \\
\hline 9447.03 & 31106.37 & $\mathrm{z}^{5} \mathrm{~F}^{o}$ & 4 & 20523.94 & $a^{5} \mathrm{G}$ & 5 & $\ldots$ & $0.29 \pm 0.04$ & -1.46 \\
\hline 9571.75 & 30965.46 & $\mathrm{z}^{5} \mathrm{~F}^{o}$ & 3 & 20520.92 & $a^{5} G$ & 3 & $\ldots$ & $0.052 \pm 0.007$ & -2.30 \\
\hline 9574.29 & 30965.46 & $\mathrm{z}^{5} \mathrm{~F}^{o}$ & 3 & 20523.69 & $a^{5} \mathrm{G}$ & 4 & $\ldots$ & $0.24 \pm 0.03$ & -1.63 \\
\hline 9667.20 & 30858.82 & $\mathrm{z}^{5} \mathrm{~F}^{o}$ & 2 & 20517.40 & $a^{5} \mathrm{G}$ & 2 & $\ldots$ & $0.045 \pm 0.006$ & -2.51 \\
\hline
\end{tabular}


Table 3-Continued

\begin{tabular}{|c|c|c|c|c|c|c|c|c|c|}
\hline $\begin{array}{l}\lambda_{\text {air }} \\
{[\AA]}\end{array}$ & $\begin{array}{c}\mathrm{E}_{\text {upper }} \\
{\left[\mathrm{cm}^{-1}\right]}\end{array}$ & Term & $\mathrm{J}_{\text {upper }}$ & $\begin{array}{c}\mathrm{E}_{\text {lower }} \\
{\left[\mathrm{cm}^{-1}\right]}\end{array}$ & Term & $\mathrm{J}_{\text {lower }}$ & $\begin{array}{c}\mathrm{A}_{L S c a l c} \\
{\left[10^{6} \mathrm{~s}^{-1}\right]}\end{array}$ & $\begin{array}{c}\mathrm{A}_{\operatorname{Exp}} \\
{\left[10^{6} \mathrm{~s}^{-1}\right]}\end{array}$ & $\log g f$ \\
\hline 9670.49 & 30858.82 & $\mathrm{z}^{5} \mathrm{~F}^{o}$ & 2 & 20520.92 & $a^{5} G$ & 3 & $\cdots$ & $0.23 \pm 0.03$ & -1.79 \\
\hline 9734.52 & 30787.30 & $\mathrm{z}^{5} \mathrm{~F}^{o}$ & 1 & 20517.40 & $a^{5} G$ & 2 & $\ldots$ & $0.27 \pm 0.04$ & -1.95 \\
\hline
\end{tabular}


Table 4. EW Measurements for the Survey Stars

\begin{tabular}{|c|c|c|c|c|c|c|}
\hline $\begin{array}{c}\lambda \\
{[\AA]}\end{array}$ & $\begin{array}{c}\chi \\
{[\mathrm{eV}]}\end{array}$ & $\log (g f)$ & $\begin{array}{c}<E W_{\text {Sun }}> \\
{[\mathrm{m} \AA]}\end{array}$ & $\begin{array}{c}<E W_{H D 75732}> \\
{[\mathrm{m} \AA]}\end{array}$ & $\begin{array}{c}<E W_{H D 140283}> \\
{[\mathrm{m} \AA]}\end{array}$ & $\begin{array}{c}<E W_{C S 22892}> \\
{[\mathrm{m} \AA]}\end{array}$ \\
\hline \multicolumn{7}{|l|}{ Cr I : } \\
\hline 3018.49 & 0.97 & -0.44 & 101.6 & $\ldots$ & $\ldots$ & $\ldots$ \\
\hline 3578.68 & 0.00 & 0.42 & $\ldots$ & $\ldots$ & 70.5 & 89.9 \\
\hline 3593.48 & 0.00 & 0.31 & $\ldots$ & $\ldots$ & 68.5 & 86.5 \\
\hline 3732.02 & 0.00 & -2.57 & 55.5 & $\ldots$ & $\ldots$ & $\ldots$ \\
\hline 3916.25 & 0.97 & -1.75 & 54.0 & $\ldots$ & $\ldots$ & $\ldots$ \\
\hline 3984.34 & 2.54 & -0.47 & 52.5 & $\ldots$ & $\ldots$ & $\ldots$ \\
\hline 4025.00 & 2.54 & -1.05 & 22.8 & $\ldots$ & $\ldots$ & $\ldots$ \\
\hline 4254.33 & 0.00 & -0.09 & $\ldots$ & $\ldots$ & 65.2 & $\ldots$ \\
\hline 4274.80 & 0.00 & -0.22 & $\ldots$ & $\ldots$ & 61.0 & $\ldots$ \\
\hline 4289.72 & 0.00 & -0.37 & $\ldots$ & $\ldots$ & 55.2 & 90.5 \\
\hline 4293.55 & 2.91 & -1.20 & 13.2 & $\ldots$ & $\ldots$ & $\ldots$ \\
\hline 4319.64 & 2.89 & -1.14 & 15.1 & 44.1 & $\ldots$ & $\ldots$ \\
\hline 4373.26 & 0.98 & -2.30 & 35.6 & 83.9 & $\ldots$ & $\ldots$ \\
\hline 4496.84 & 0.94 & -1.14 & 82.7 & $\ldots$ & 3.9 & $\ldots$ \\
\hline 4529.84 & 2.54 & -1.35 & 17.1 & $\ldots$ & $\ldots$ & $\ldots$ \\
\hline 4535.12 & 2.54 & -1.02 & 29.5 & 68.0 & $\ldots$ & $\ldots$ \\
\hline 4541.06 & 2.54 & -1.15 & 24.3 & $\ldots$ & $\ldots$ & $\ldots$ \\
\hline 4545.95 & 0.94 & -1.37 & 78.2 & 131.9 & 2.8 & $\ldots$ \\
\hline 4591.39 & 0.97 & -1.74 & 61.9 & $\ldots$ & $\ldots$ & $\ldots$ \\
\hline 4600.74 & 1.00 & -1.25 & 77.8 & $\ldots$ & 2.7 & $\ldots$ \\
\hline 4613.36 & 0.96 & -1.65 & 66.2 & $\ldots$ & $\ldots$ & $\ldots$ \\
\hline 4616.12 & 0.98 & -1.19 & 81.0 & 136.8 & $\ldots$ & $\ldots$ \\
\hline 4626.17 & 0.97 & -1.33 & 76.1 & $\ldots$ & 2.6 & $\ldots$ \\
\hline 4628.47 & 3.14 & -1.40 & 6.1 & 34.7 & $\ldots$ & $\ldots$ \\
\hline 4633.26 & 3.13 & -1.11 & 9.0 & 38.2 & $\ldots$ & $\ldots$ \\
\hline 4639.50 & 3.11 & -0.91 & 15.1 & $\ldots$ & $\ldots$ & $\ldots$ \\
\hline 4646.15 & 1.03 & -0.74 & 92.0 & $\ldots$ & $\ldots$ & 16.9 \\
\hline 4651.28 & 0.98 & -1.46 & 73.7 & 132.1 & $\ldots$ & $\ldots$ \\
\hline
\end{tabular}


Table 4-Continued

\begin{tabular}{|c|c|c|c|c|c|c|}
\hline $\begin{array}{c}\lambda \\
{[\AA]}\end{array}$ & $\begin{array}{c}\chi \\
{[\mathrm{eV}]}\end{array}$ & $\log (g f)$ & $\begin{array}{c}<E W_{\text {Sun }}> \\
{[\mathrm{m} \AA]}\end{array}$ & $\begin{array}{c}<E W_{H D 75732}> \\
{[\mathrm{m} \AA]}\end{array}$ & $\begin{array}{c}<E W_{H D 140283}> \\
{[\mathrm{m} \AA]}\end{array}$ & $\begin{array}{c}<E W_{C S 22892}> \\
{[\mathrm{m} \AA]}\end{array}$ \\
\hline 4652.15 & 1.00 & -1.04 & 92.0 & $\ldots$ & 5.4 & 9.7 \\
\hline 4689.38 & 3.13 & -0.40 & 36.0 & $\ldots$ & $\ldots$ & $\ldots$ \\
\hline 4695.15 & 2.98 & -1.12 & 15.3 & $\ldots$ & $\ldots$ & $\ldots$ \\
\hline 4708.02 & 3.17 & 0.07 & 53.8 & 92.8 & $\ldots$ & $\ldots$ \\
\hline 4718.43 & 3.20 & 0.24 & 62.5 & 105.7 & $\ldots$ & $\ldots$ \\
\hline 4745.27 & 2.71 & -1.38 & 11.7 & $\ldots$ & $\ldots$ & $\ldots$ \\
\hline 4789.34 & 2.54 & -0.33 & 59.2 & 99.9 & $\ldots$ & $\ldots$ \\
\hline 4790.34 & 2.54 & -1.48 & 12.5 & 48.9 & $\ldots$ & $\ldots$ \\
\hline 4885.96 & 3.09 & -1.12 & 12.8 & $\ldots$ & $\ldots$ & $\ldots$ \\
\hline 4936.34 & 3.11 & -0.25 & 42.4 & 75.4 & $\ldots$ & $\ldots$ \\
\hline 4953.71 & 3.12 & -1.48 & 4.2 & 22.6 & $\ldots$ & $\ldots$ \\
\hline 5177.42 & 3.43 & -0.53 & 18.1 & $\ldots$ & $\ldots$ & $\ldots$ \\
\hline 5200.21 & 3.38 & -0.58 & 20.8 & 56.6 & $\ldots$ & $\ldots$ \\
\hline 5220.91 & 3.38 & -0.89 & 9.8 & $\ldots$ & $\ldots$ & $\ldots$ \\
\hline 5225.81 & 2.71 & -1.50 & 12.8 & $\ldots$ & $\ldots$ & $\ldots$ \\
\hline 5238.96 & 2.71 & -1.27 & 14.9 & 47.9 & $\ldots$ & $\ldots$ \\
\hline 5241.45 & 2.71 & -1.92 & 3.4 & 19.5 & $\ldots$ & $\ldots$ \\
\hline 5243.36 & 3.39 & -0.58 & 18.6 & 58.9 & $\ldots$ & $\ldots$ \\
\hline 5247.57 & 0.96 & -1.59 & 77.6 & 125.2 & $\ldots$ & $\ldots$ \\
\hline 5255.13 & 3.46 & -0.10 & 34.3 & $\ldots$ & $\ldots$ & $\ldots$ \\
\hline 5265.16 & 3.43 & -0.35 & 24.5 & $\ldots$ & $\ldots$ & $\ldots$ \\
\hline 5287.20 & 3.44 & -0.87 & 9.8 & 33.5 & $\ldots$ & $\ldots$ \\
\hline 5296.69 & 0.98 & -1.36 & 87.6 & 144.9 & $\ldots$ & 8.0 \\
\hline 5300.74 & 0.98 & -2.00 & 54.2 & 103.3 & $\ldots$ & $\ldots$ \\
\hline 5304.18 & 3.46 & -0.67 & 14.4 & 42.9 & $\ldots$ & $\ldots$ \\
\hline 5318.81 & 3.44 & -0.67 & 13.7 & 45.5 & $\ldots$ & $\ldots$ \\
\hline 5340.47 & 3.44 & -0.73 & 12.9 & $\ldots$ & $\ldots$ & $\ldots$ \\
\hline 5345.80 & 1.00 & -0.95 & 107.2 & 187.7 & 5.4 & 13.1 \\
\hline 5348.31 & 1.00 & -1.21 & 93.4 & 161.3 & 3.2 & 85.0 \\
\hline
\end{tabular}


Table 4-Continued

\begin{tabular}{|c|c|c|c|c|c|c|}
\hline $\begin{array}{c}\lambda \\
{[\AA]}\end{array}$ & $\begin{array}{c}\chi \\
{[\mathrm{eV}]}\end{array}$ & $\log (g f)$ & $\begin{array}{c}<E W_{\text {Sun }}> \\
{[\mathrm{m} \AA]}\end{array}$ & $\begin{array}{c}<E W_{H D 75732}> \\
{[\mathrm{m} \AA]}\end{array}$ & $\begin{array}{c}<E W_{H D 140283}> \\
{[\mathrm{m} \AA]}\end{array}$ & $\begin{array}{c}<E W_{C S 22892}> \\
{[\mathrm{m} \AA]}\end{array}$ \\
\hline 5409.77 & 1.03 & -0.67 & 125.7 & $\ldots$ & 10.0 & 20.5 \\
\hline 5628.62 & 3.42 & -0.74 & 14.0 & 44.2 & $\ldots$ & $\ldots$ \\
\hline 5712.75 & 3.01 & -1.03 & 14.7 & 51.1 & $\ldots$ & $\ldots$ \\
\hline 5719.81 & 3.01 & -1.58 & 4.2 & 20.8 & $\ldots$ & $\ldots$ \\
\hline 5781.16 & 3.01 & -1.00 & 14.1 & 46.7 & $\ldots$ & $\ldots$ \\
\hline 5844.59 & 3.01 & -1.77 & 3.8 & 21.5 & $\ldots$ & $\ldots$ \\
\hline \multicolumn{7}{|l|}{ Cr II : } \\
\hline 3382.69 & 2.45 & -0.98 & 100.3 & $\ldots$ & 39.6 & 55.1 \\
\hline 3391.44 & 2.45 & -1.40 & 83.9 & $\ldots$ & 22.4 & 31.9 \\
\hline 3393.85 & 3.10 & -0.99 & 82.6 & $\ldots$ & 16.7 & $\ldots$ \\
\hline 3408.81 & 2.48 & -0.42 & $\ldots$ & $\ldots$ & 54.0 & 67.0 \\
\hline 3511.84 & 2.48 & -1.46 & 73.3 & $\ldots$ & 13.7 & 29.4 \\
\hline 3585.52 & 2.71 & -1.39 & 83.2 & $\ldots$ & $\ldots$ & $\ldots$ \\
\hline 3715.18 & 3.10 & -1.37 & $\ldots$ & $\ldots$ & 6.5 & 11.1 \\
\hline 4558.65 & 4.07 & -0.66 & 76.8 & 81.8 & 6.8 & $\ldots$ \\
\hline 4588.20 & 4.07 & -0.83 & 70.4 & 75.5 & 5.1 & $\ldots$ \\
\hline 4592.05 & 4.07 & -1.42 & 47.4 & $\ldots$ & 0.9 & $\ldots$ \\
\hline 4634.08 & 4.07 & -0.98 & 59.4 & $\ldots$ & 1.7 & 1.9 \\
\hline 4848.25 & 3.86 & -1.00 & 60.7 & 70.4 & 2.3 & 3.7 \\
\hline
\end{tabular}


Table 5. Solar Photospheric Cr I and Cr II Abundances for Different Models ${ }^{\mathrm{a}}$

\begin{tabular}{lcccc}
\hline \hline \multicolumn{1}{c}{ Model } & $\log \epsilon(\mathrm{CrI})_{\odot}$ & $\sigma$ & $\log \epsilon(\mathrm{CrII})_{\odot}$ & $\sigma$ \\
& & & & \\
\hline Holweger-Müller (1974) & $5.64 \pm 0.01$ & 0.07 & $5.77 \pm 0.03$ & 0.13 \\
ATLAS (Kurcuz 1993) & $5.52 \pm 0.01$ & 0.08 & $5.69 \pm 0.03$ & 0.13 \\
Asplund et al. (2004) & $5.49 \pm 0.01$ & 0.08 & $5.70 \pm 0.03$ & 0.13 \\
Grevesse \& Sauval (1999) & $5.58 \pm 0.01$ & 0.09 & $5.74 \pm 0.03$ & 0.13 \\
NEW MARCS (Gustafsson et al. 2003) & $5.53 \pm 0.01$ & 0.08 & $5.67 \pm 0.03$ & 0.13 \\
MARCS (Gustafsson et al. 1975) & $5.52 \pm 0.01$ & 0.07 & $5.68 \pm 0.03$ & 0.13 \\
\hline
\end{tabular}

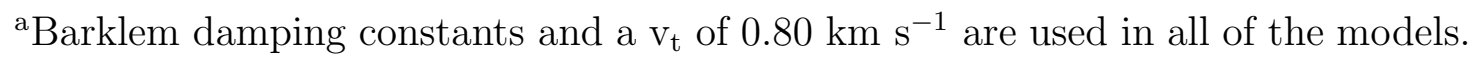


Table 6. Comparison to the Blackwell et al. 1987 Solar Abundances ${ }^{\mathrm{a}}$

\begin{tabular}{|c|c|c|c|c|c|c|c|c|c|c|c|c|}
\hline $\begin{array}{c}\lambda \\
{[\AA]}\end{array}$ & $\begin{array}{c}\chi \\
{[\mathrm{eV}]}\end{array}$ & $\begin{array}{l}\text { Upper } \\
\text { Term }\end{array}$ & $\underset{\mathrm{J}}{\text { Upper }}$ & $\begin{array}{l}\text { Lower } \\
\text { Term }\end{array}$ & $\begin{array}{c}\text { Lower } \\
\mathrm{J}\end{array}$ & $\log (g f)_{\text {Blackwell }}$ & $\log (g f)_{\text {Sobeck }}$ & $\begin{array}{c}\mathrm{EW}_{M o o r e} \\
{[\mathrm{~m} \AA]}\end{array}$ & 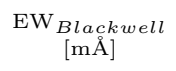 & $\begin{array}{c}\mathrm{EW}_{\text {Sobeck }} \\
{[\mathrm{m} \AA]}\end{array}$ & $\log \epsilon_{\text {Blackwell }}$ & $\log \epsilon_{\text {Sobeck }}$ \\
\hline 5247.57 & 0.96 & $\mathrm{z}^{5} \mathrm{P}^{o}$ & 1 & $a^{5} D$ & 0 & -1.59 & -1.63 & 76 & 80.1 & 77.6 & 5.81 & 5.71 \\
\hline 5264.16 & 0.97 & $\mathrm{z}^{5} \mathrm{P}^{o}$ & 1 & $a^{5} \mathrm{D}$ & 1 & $\ldots$ & -1.25 & $\ldots$ & $\ldots$ & $\ldots$ & $\ldots$ & $\ldots$ \\
\hline 5265.72 & 0.97 & $\mathrm{z}^{5} \mathrm{P}^{\circ}$ & 2 & $a^{5} D$ & 1 & $\ldots$ & -1.71 & $\ldots$ & $\ldots$ & $\ldots$ & $\ldots$ & $\ldots$ \\
\hline 5296.69 & 0.98 & $\mathrm{z}^{5} \mathrm{P}^{o}$ & 1 & $a^{5} D$ & 2 & -1.36 & -1.39 & $\ldots$ & $\ldots$ & 87.6 & & 5.70 \\
\hline 5298.28 & 0.98 & $\mathrm{z}^{5} \mathrm{P}^{o}$ & 2 & $a^{5} D$ & 2 & -1.14 & -1.17 & $\ldots$ & $\ldots$ & $\ldots$ & $\ldots$ & \\
\hline 5300.74 & 0.98 & $\mathrm{z}^{5} \mathrm{P}^{o}$ & 3 & $a^{5} D$ & 2 & -2.00 & -2.13 & 56 & 56.3 & 54.2 & 5.78 & 5.60 \\
\hline 5345.80 & 1.00 & $\mathrm{z}^{5} \mathrm{P}^{o}$ & 2 & $a^{5} D$ & 3 & -0.95 & -0.98 & 107 & 116.9 & 107.2 & 5.85 & 5.66 \\
\hline 5348.31 & 1.00 & $\mathrm{z}^{5} \mathrm{P}^{o}$ & 3 & $a^{5} D$ & 3 & -1.21 & -1.29 & 92 & $\ldots$ & 93.4 & $\ldots$ & 5.67 \\
\hline 5409.77 & 1.03 & $\mathrm{z}^{5} \mathrm{P}^{\circ}$ & 3 & $a^{5} D$ & 4 & -0.67 & -0.72 & & $\ldots$ & 125.7 & $\ldots$ & 5.64 \\
\hline
\end{tabular}

${ }^{\mathrm{a}}$ For abundance derivation, both studies employed the Holweger-Müller model. Note that Blackwell et al. used a slightly higher $\mathrm{vt}_{\mathrm{t}}$ of $0.85 \mathrm{~km} \mathrm{~s}^{-1}$. 